\title{
Implementing The Multi Expression Programming, Nonlinear Regression, Artificial Neural Network, and M5P-Tree Models to Predict The Long-Term of Compressive Strength of Cement- Mortar Modified With Fly Ash
}

\section{Aso Abdalla}

University of Sulaimani

Ahmed Mohammed ( $\square$ ahmed.mohammed@univsul.edu.iq )

University of Sulaimani https://orcid.org/0000-0003-4306-3274

\section{Research Article}

Keywords: Fly ash, Cement-mortar, Long-term compressive strength, MEP Model, Sensitivity

Posted Date: January 3rd, 2022

DOI: https://doi.org/10.21203/rs.3.rs-1123704/v1

License: (9) (1) This work is licensed under a Creative Commons Attribution 4.0 International License. Read Full License 


\section{Abstract}

In the recent decade, supplementary cementing ingredients have become an essential part of various strength ranges of concrete and cement-mortar mix design. Examples are natural materials, by-products, industrial wastes, and materials that require less energy and time to generate. Fly ash is one of the most widely utilized additional cementing ingredients. Fly ash is a by-product substance produced by coal combustion. It's being used in cement mortar and concrete as a pozzolanic substance. It has demonstrated significant influence in improving liquid and solid properties of cement mortar, such as compressive strength. Multi Expression Programming (MEP) is employed in this study to estimate the compressive strength (CS) of cement mortar modified with fly ash. The outcomes of this model were compared and evaluated with several other models such as the Nonlinear Regression model (NLR), Artificial Neural Network (ANN), and M5P-tree models that have been used in the construction fields. The input parameters included water/cement ratio (w/c), curing time (t days), and fly ash content (FA \%), while the target property was compressive strength up to 360 days of curing. Four hundred fifty (450) data are collected from previous literature on modifying cement mortar with fly ash for that purpose. The water/cement ratio ranged from 0.24 to 1.2 , and the fly ash was used to replace cement up to $55 \%$ (\%wt. of dry cement). Based on the Coefficient of Determination $\left(\mathrm{R}^{2}\right)$, Root Mean Squared Error (RMSE), Scatter Index (SI), Objective $(\mathrm{OBJ})$, Mean Absolute Error (MAE), t-test value, the uncertainty of $95 \%$, Performance Index $(\rho)$, and boxplot for actual and predicted compressive strength. The MEP model performed better than other developed models according to evaluation tools. The compressive strength was also correlated with flexural and splitting tensile strengths using different nonlinear models.

\section{Introduction}

Management of industrial waste materials is a global problem; fly ash (FA) is a waste -product of power plants resulting from coal combustion. Supplementary cementitious materials (SCM) are those materials that are used in concrete plants to replace Portland cement in cement-based mortar and cement-based concrete. The hydration of cement with water forming calcium silicate hydroxide gel (C-S-H) and calcium silicate (C-H), SCM like fly ash reacted with $\mathrm{C}-\mathrm{H}$ and resulted in the formation of further $\mathrm{C}-\mathrm{S}-\mathrm{H}$ and solving the durability problems related to $\mathrm{C}-\mathrm{H}$ which is vulnerable to chemical attack (Abed 2018). Fly ash modified cementitious material generate less heat during the hydration process; therefore, it is suitable for mass concrete (Fraay et al. 1989; Gartner 2004; Rahhal and Talero 2004; Peter 2005; Sakai et al. 2005), and their strength is greatly influenced by the physical characteristics and chemical composition of the fly ash; those properties depend on the coal type and the equipment used in the power plant and the reactivity of the fly ash (Sakai et al. 2005; Otsuka et al. 2009). The pozzolanic reactivity of fly ash has been investigated in various research. Pozzolanic reactivity of fly ash can be measured through chemical analysis to determine the quantity of silica or measuring the heat developed at the hydration time. However, since the silicate forms a gel at a pH greater than 10, the amount of silica used in the gel formation must be considered (Hassett and Eylands 1997; Bumrongjaroen et al. 2007). After 28 days of curing, the consumption of C-H through a pozzolanic reaction of fly ash can be measured by X-Ray diffraction (XRD) or thermal analysis (Giergiczny 2004; Baert et al. 2008). 
Cho et al. (2019) evaluated the effect of fly ash chemical composition on the compressive strength of fly ash modified cement mortar using sixteen different types of fly ashes for replacing cement in cement mortar. They concluded that the pozzolanic reactively of fly ash is mainly affected by the percentage of $\mathrm{SiO}_{2}, \mathrm{Al}_{2} \mathrm{O}_{3}$, and $\mathrm{Fe}_{2} \mathrm{O}_{3}$, and the fly ash effect on compressive strength at 90 days of curing is greater than compressive strength at 28 days of curing. Chindaprasirt et al. (2004) studied the effect of fly ash fineness on the mechanical properties, sulfate resistance, and drying shrinkage of cement mortar. The study results showed that fly ash with higher fineness improves strength, drying shrinkage, and sulfate attack.

Chindaprasirt et al. (2008) evaluated workability and chloride ion resistance of cement mortar modified with fly ash. Replacement of cement with fly ash improved resistance to Chloride ion penetration and better workability for the cement mortar.

Modeling the properties of materials can be performed in various ways, including computational modeling, statistical techniques, and newly created tools like Regression analysis, M5P-tree, and artificial neural networks (ANN) (Sihag et al. 2018; Mahmood and Mohammed 2019; Qadir et al. 2019b; Vipulanandan and Mohammed 2019; Marangu 2020).

Mohammed et al. (2020a) used ANN, M5P tree, and nonlinear regression to predict the compressive strength of cement-based mortar modified with fly ash. They have concluded that the ANN model can be used efficiently with a high correlation coefficient (R) and minimum RMSE. ANN model was also used by Apostolopoulou et al. (2019) to predict the compressive strength of natural hydraulic lime; the results revealed that ANN could accurately forecast the CS of natural hydraulic lime mortars, implying that they can be used as a decision-making tool when developing natural hydraulic lime mortars. Also, Armaghani and Asteris (2021) investigated the application of ANN and adaptive neuro-fuzzy inference system (ANFIS) models to predict the compressive strength of cement mortar with or without metakaolin concluded that ANFIS performed better than ANN. At the same time, overfitting was observed for some of the data.

Moreover, Suba (2009) employed ANN for mechanical properties prediction and compared the result with linear regression, the forecast of the ANN model was pretty close to actual work. MEP was used to estimate the mechanical properties of concrete and provide acceptable results as implemented by Shah et al. (2021). The parametric study revealed the accuracy of the MEP model, with a high correlation coefficient (R). As a result, several techniques were used in the literature to forecast the mechanical properties of cement-based mortar, but MEP has not been used for that purpose.

In this study, the MEP model was used to predict the compressive strength of the fly ash modified cementmortar using 450 data collected from previous research related to modified cement-based mortar, and outcomes were compared with different approaches, including ANN, nonlinear regression, M5P-tree, and nonlinear model. The various statistical evaluations were applied to assess the accuracy of the models. The correlation between the compressive with flexural and splitting strengths of fly ash-modified cement-based mortar using different nonlinear models.

\section{Objectives}


This study is aimed to investigate the application of the MEP model to forecast the compressive strength of cement-based mortar with or without fly ash up to 360 days curing; the followings are the main objectives:

(i). Statistically analyze the collected data to evaluate the effect of the mix proportion of cement-based mortar modified with fly ash on the compressive strength.

(ii). Developing a reliable model to predict the compressive strength of cement mortar modified with fly ash and obtaining the sensitivity of the models using different statistical approaches.

(iii). Correlating compressive strength of the cement mortar with flexural and splitting tensile strengths of the cement mortar modified with fly ash.

\section{Methodology}

Figure 1 presents the steps that have been followed during this study. The following are steps of the current study methodology:

- Collecting a considerable number of the datasets (450 datasets) from different published studies in reputable journals.

- Considering w/c, curing time, and fly ash content as independent variables for predictors and compressive strength of the cement-based mortar as a target.

- Dividing the collected data into three datasets, 70\% for training, 30\% for testing and validation.

- Statistical analysis, visualizing data, and determining the correlation between independent and dependent variables.

- Modeling the compressive strength using MEP, NLR, ANN, and M5P-tree models.

- Evaluating developed models based on $\mathrm{R}^{2}$, RMSE, SI, MAE, OBJ, t-test, 95\% uncertainty, and performance index for actual and predicted compressive strength.

- Performing sensitivity analysis to detect the most dominant parameter on the compressive strength of cement-based mortar modified with fly ash.

\subsection{Data collection}

A comprehensive 450 data on compressive strength and flexural strength data on cement-based mortar modified with fly ash were collected from different literature (Xu et al. 1993; Wong et al. 1999; Puertas et al. 2003; Türkel and Altuntaş 2009; De Weerdt et al. 2011; Sasiekalaa and Malathy 2012; Yerramala and Desai 2012; Alwash 2013; Jung and Kwon 2013; Mishra and Deodhar 2013; Tan et al. 2013; Biricik and Sarier 2014; Demir et al. 2018; Qadir et al. 2019a; Burhan et al. 2020; Mohammed et al. 2020a). The dataset was divided into three groups (training, testing, and validating) randomly using the Rand function in Microsoft Excel. The largest group included $70 \%$ of the dataset (300 data), and each of the other two groups had 15\% of the dataset (75 data). The training data is used to develop the model while validating and testing data is provided to test the developed model against unseen data. The overfitting of the developed model can be 
minimized (Rai et al. 2014). The summary of statistical analysis on the input and output parameters with detail of the collected data is shown in Table 1. 
Table 1

Summary of statistical analysis of model input parameters

\begin{tabular}{|c|c|c|c|c|c|c|}
\hline References & $\begin{array}{l}\text { Water to } \\
\text { cement } \\
\text { ratio }(w / c)\end{array}$ & $\begin{array}{l}\text { Curing } \\
\text { time, } t \\
\text { (Days) }\end{array}$ & $\begin{array}{l}\text { Fly ash } \\
\text { content, } \\
\text { FA (\%) }\end{array}$ & $\begin{array}{l}\text { Compressive } \\
\text { strength ,CS } \\
\text { (MPa) }\end{array}$ & $\begin{array}{l}\text { Flexural } \\
\text { strength, FS } \\
\text { (MPa) }\end{array}$ & $\begin{array}{l}\text { Splitting } \\
\text { tensile } \\
\text { strength, } \\
\text { STS } \\
\text { (MPa) }\end{array}$ \\
\hline $\begin{array}{l}\text { Qadir et al. } \\
\text { (2019) }\end{array}$ & $0.30-1.2$ & $\begin{array}{l}1,3,7 \\
28,90 \\
\text { and } 360\end{array}$ & $0-50$ & $16-55$ & & \\
\hline $\begin{array}{l}\text { Yerramala } \\
\text { and Desai } \\
(2012)\end{array}$ & 0.5 & $\begin{array}{l}7,28 \\
\text { and } 90\end{array}$ & $0-25$ & $10-32$ & & $1.5-4$ \\
\hline $\begin{array}{l}\text { Biricik and } \\
\text { Sarier (2014) }\end{array}$ & 0.48 & $\begin{array}{l}7,14,28, \\
56, \text { and } \\
90\end{array}$ & $0-55$ & $3.9-30$ & & $1.2-3$ \\
\hline $\begin{array}{l}\text { Burhan et al. } \\
(2020)\end{array}$ & $0.5-0.58$ & 28 & $0-18$ & $7-12$ & & \\
\hline $\begin{array}{l}\text { Xu et al. } \\
\text { (1993) }\end{array}$ & 0.46 & $\begin{array}{l}1,3,7 \\
\text { and } 28\end{array}$ & $0-40$ & $7-60$ & $2-8$ & \\
\hline $\begin{array}{l}\text { Wong et al. } \\
\text { (1999) }\end{array}$ & 0.3 & $\begin{array}{l}28, \text { and } \\
90\end{array}$ & $0-55$ & $70-81$ & $5-14$ & $1.5-3.8$ \\
\hline $\begin{array}{l}\text { Mohammed } \\
\text { et al. (2020) }\end{array}$ & $0.5-0.62$ & $7,28,90$ & $0-20$ & $29-56$ & & \\
\hline $\begin{array}{l}\text { Demir et al. } \\
\text { (2018) }\end{array}$ & $0.4-0.49$ & $\begin{array}{l}3,7,28 \\
90\end{array}$ & $\begin{array}{l}30 \text { and } \\
55\end{array}$ & $16-37$ & & \\
\hline $\begin{array}{l}\text { Jung and } \\
\text { Kwon (2013) }\end{array}$ & 0.44 & $\begin{array}{l}3,7,28 \\
50\end{array}$ & $0-30$ & $23-54$ & & \\
\hline $\begin{array}{l}\text { Mishra and } \\
\text { Deodhar } \\
\text { (2013) }\end{array}$ & 0.5 & 7,28 & $0-50$ & $26-40$ & $3-7$ & \\
\hline $\begin{array}{l}\text { Türkel and } \\
\text { Altuntaş } \\
\text { (2009) }\end{array}$ & 0.5 & $2,7,28$ & 30 & $19-50$ & & \\
\hline $\begin{array}{l}\text { Puertas et al. } \\
\text { (2003) }\end{array}$ & 0.5 & $1,28,90$ & $0-35$ & $12-72$ & $3-9$ & \\
\hline $\begin{array}{l}\text { De Weerdt et } \\
\text { al. (2011) }\end{array}$ & $0.32-0.38$ & 28 & 10 & $45-84$ & & \\
\hline $\begin{array}{l}\text { Sasiekalaa } \\
\text { and Malathy } \\
(2012)\end{array}$ & 0.56 & $7,28,90$ & $0-20$ & $23-43$ & $4-7$ & \\
\hline $\begin{array}{l}\text { Alwash } \\
\text { (2013) }\end{array}$ & $0.24-0.8$ & $\begin{array}{l}1,3,7 \\
14,90\end{array}$ & $0-35$ & $12-60$ & $3-8$ & \\
\hline
\end{tabular}




\begin{tabular}{|lllllll|}
\hline References & $\begin{array}{l}\text { Water to } \\
\text { cement } \\
\text { ratio (w/c) }\end{array}$ & $\begin{array}{l}\text { Curing } \\
\text { time, } \\
\text { (Days) }\end{array}$ & $\begin{array}{l}\text { Fly ash } \\
\text { content, } \\
\text { FA (\%) }\end{array}$ & $\begin{array}{l}\text { Compressive } \\
\text { strength ,CS } \\
\text { (MPa) }\end{array}$ & $\begin{array}{l}\text { Flexural } \\
\text { strength, FS } \\
\text { (MPa) }\end{array}$ & $\begin{array}{l}\text { Splitting } \\
\text { tensile } \\
\text { strength, } \\
\text { STS } \\
\text { (MPa) }\end{array}$ \\
\hline $\begin{array}{l}\text { Tan et al. } \\
(2013)\end{array}$ & 0.5 & $7,14,28$ & $0-7$ & $19-31$ & & \\
\hline Min & 0.24 & 1 & 0 & 3.9 & 0.5 & 1.2 \\
\hline Max & 1.2 & 360 & 55 & 84 & 14 & 4 \\
\hline Mean & 0.44 & 28 & 6.77 & 32.94 & 6.13 & 2.65 \\
\hline SD & 0.18 & 51 & 11.87 & 14.02 & 1.878 & 0.836 \\
\hline
\end{tabular}

\subsection{Statistical analysis}

\section{(i) Water to cement ratio (w/c)}

According to the statistical evaluation on the collected data, w/c was ranged between 0.24 to 1.2 , with mean, Standard Deviation (SD), Variance (Var), Skewness (Skew), and Kurtosis (Kur) of 0.44, 0.18, 0.03, $1.34,3.32$, respectively. The relation between $\mathrm{w} / \mathrm{c}$ and compressive strength and the histogram for $\mathrm{w} / \mathrm{c}$ is shown in Fig. 2 (a).

\section{(ii) Curing time (t), (days)}

The collected dataset contained experimental results from previous studies; the curing time ranged from 1 to 360 days, with a median of 7 days, SD, Var, Skew, and Kur of 51 days, 2672.98 4.19, 21.64, respectively. The histogram for curing time and variation of compressive strength with curing time are presented in Fig. 2 (b).

\section{(iii) Fly ash content, FA (\%)}

Based on the collected data from the literature, the maximum percentage of cement replacement with fly ash was $55 \%$. With a mean, SD, Var, Skew, and Kur of $6.77 \%, 11.87,140.97,1.76,2.13$, respectively. The variation of compressive strength with the percentage of the replacement of fly ash content and histogram for fly ash content is displayed in Fig. 2 (c).

\section{(iv) Compressive strength (CS)}

From 450 datasets, the compressive strength of cement-based mortar modified with fly ash up to 360 days was ranged from 3.9 to $84 \mathrm{MPa}$, with a median of $30.3 \mathrm{MPa}$, SD, Var, Skew, and Kur of $14.02 \mathrm{MPa}$, 196.59, 0.57 , and 0.18 , respectively. The histogram of compressive strength of cement-based mortar modified with fly ash and Weibull Distribution Function is shown in Fig. 3 (a).

(v) Flexural strength (FS) 
Based on 56 data of the tested sample collected from literature, flexural strength for cement-based mortar up to 360 days was ranged from 0.5 to $8.5 \mathrm{MPa}$, with a Median of 6.8, SD, Var, Skew, and Kur of $1.88 \mathrm{MPa}$, $3.526,-1.01$, and 0.394 , respectively. The histogram for flexural strength and smallest extreme value distribution function is shown in Fig. 3 (b).

\section{(vi) Splitting tensile strength (STS)}

According to the 26 data collected from previous research about fly ash modified cement-based mortar up to 360 days, the splitting tensile strength was varied from 1.2 to $4 \mathrm{MPa}$, with a median of $2.77 \mathrm{MPa}$. SD, Var, Skew, Kur of $0.837 \mathrm{MPa}, 0.7,-0.229,-1.212$, respectively. The histogram for splitting tensile strength with the smallest extreme value distribution function is displayed in Fig. 3 (c)

\subsection{Modeling}

From the correlation between independent variables and dependent variable direct relationship between cement-based- mortar compositions and compressive strength were not observed; as can be seen from the correlation matrix (Fig. 4), the correlation coefficient (R) of CS with w/c, curing time, and fly ash content are $-0.386,0.541,-0.279$, respectively. Accordingly, the relations are poor between dependent and independent variables, which means that the compressive strength of the cement-mortar is a multivariable function. Therefore, MEP is used to develop a model to predict the compressive strength of cement-based mortar modified with fly ash based on the cement-mortar composition such as w/c, curing time, and fly ash content.

\subsubsection{Multi-Expression-Programing (MEP model)}

Genetic Algorithm (GA) was first introduced by Holland (1992), which was motivated through evolution theory, similar to that of Genetic Programming (GP) proposed by Cramer (Cramer 1985; Holland 1992; Koza and Koza 1992). Several linear variations of GP have already been proposed to deal with some difficulties (such as bloat) caused by tree representations of GP. A few examples are Cartesian Genetic Programming, Grammatical Evolution (GE), Linear GP, and Gene Expression Programming (Oltean and Dumitrescu 2002). MEP individuals are strings of genes encoding complex computer programs; when MEPs package expressions for conceptual regression issues, they comparably represent them to how processors convert $C$ or Pascal expressions into machine code (Aho et al. 2020). Multiple solutions are stored in a separate chromosome in MEP individuals. The most acceptable option is generally chosen. This is known as strong implicit parallelism, and it is a distinctive characteristic of MEP (Handley 1994; Brameier and Banzhaf 2001). This feature does not make MEP more complex when compared with GE and GEP. The MEP model incorporates different fitting factors to generate a generalized relationship. Simple math operators were employed to generate simple expressions in this investigation, and a trial-and-error procedure was used to determine the fitting parameters (Mousavi et al. 2010), as presented in Table 2. 
Table 2

Optimal parameters for MEP model

\begin{tabular}{|ll|}
\hline Parameters & Setting \\
\hline Subpopulations number & 50 \\
\hline Subpopulation size & 200 \\
\hline Code length & 50 \\
\hline Probability of crossover & 0.9 \\
\hline Mathematical operator & $\mathbf{+ , ~ - ~ * , ~ / ~}^{*}$ \\
\hline Probability of alteration & 0.01 \\
\hline Competition size & 4 \\
\hline Functions probability & 0.5 \\
\hline Variables probability & 0.5 \\
\hline Generations & 1000 \\
\hline
\end{tabular}

\subsubsection{Nonlinear regression model (NLR)}

The following formula can be considered a general form for developing a nonlinear regression model (Demircan et al. 2011; Rai et al. 2014) to predict the compressive strength from the cement-mortar components, including the FA content (Eq. 1).

$C S=\beta_{1}\left(\frac{w}{c}\right)^{\beta_{2}}(t)^{\beta_{3}}+\beta_{4}\left(\frac{w}{c}\right)^{\beta_{5}}(t)^{\beta_{6}(F A)^{\beta_{7}}}$

$\mathrm{CS}, \mathrm{w} / \mathrm{c}, \mathrm{t}$, and FA are compressive strength, water to cement ratio, curing time, fly ash content, and $\beta_{1}$ to $\beta_{7}$ are model parameters.

\subsubsection{ANN model}

The Artificial Neural Network (ANN) is a computing system that resembles the human brain and its information analyzes. In addition, this model is a machine learning system employed in construction engineering for various numerical forecasts and difficulties (Thongsanitgarn et al. 2012; Sihag et al. 2018; Marangu 2020). ANN consists of three layers input, hidden, and output layer; these layers are connected through biases and weights. The behavior of an ANN network is influenced by the connections of neurons pattern, which also determines the class of the network. It is possible to train a network to enhance network performance. In more technical terms, the topology of the network and connection weights change repeatedly such that the error at each output layer node is minimized (Armaghani and Asteris 2021). In this study, a multi-layer feed-forward network was designed with mortar composition (w/c, t, FA) as input and CS as output, and a sigmoid activation function is used in the output layer. 
Output $=f\left(\sum_{j=1}^{n} W_{j} X_{j}+\right.$ bias $)$

Where $j$ is the number of input variables, $x_{j}$ is the input number $j$, and bias is the threshold for sigmoid activation function. The typical process of the result of ANN is illustrated in Fig. 5.

\subsubsection{M5P-tree model}

Quinlan (1992) first devised the M5 algorithm, which was developed into the M5P-tree algorithm (Wang and Witten 1996). One of the most significant advantages of model trees is their ability to efficiently solve problems, dealing with many data sets with a substantial number of attributes and dimensions. They are also noted for being powerful while dealing with missing data. The M5P-tree approach establishes a linear regression at the terminal node by classifying or partitioning diverse data areas into numerous separate spaces. It fits on each sub-location in a multivariate linear regression model. The error is estimated based on the default variance value inserted into the node. The general formula for the M5P-tree model is shown in Eq. 3.

$C S=a+b\left(\frac{w}{c}\right)+C(t)+d(F A)$

$\mathrm{CS}, \mathrm{w} / \mathrm{c}, \mathrm{t}$, and FA are compressive strength, water to cement ratio, curing time, fly ash content, and a, b, c, and $d$ are model parameters (Table 3 ).

Table 3

Model parameters for M5P-tree model

\begin{tabular}{|lllll|}
\hline LM & \multicolumn{5}{l|}{$C S=a+b\left(\frac{w}{c}\right)+c(t)+d(F A)$} \\
\cline { 2 - 5 } & \multicolumn{4}{l}{ Model Parameters } \\
\hline & a & b & c & d \\
\hline $\mathbf{1}$ & 37.420 & -53.972 & 1.942 & 0.196 \\
\hline $\mathbf{2}$ & 36.267 & -38.455 & 0.601 & 0.001 \\
\hline $\mathbf{3}$ & 29.691 & -18.188 & 0.521 & -0.102 \\
\hline
\end{tabular}

\subsubsection{Correlation of compressive strength with flexural and splitting tensile strengths}

\section{(i) Vipulanandan Correlation Model}

A Vipulanandan correlation model was used to develop the relationship between CS and FS of cement mortar modified with fly ash (Vipulanandan and Mohammed 2014; Mohammed 2017; Mohammed and 
Mahmood 2018a, 2018b; Mohammed 2018; Vipulanandan et al. 2018; Qadir et al. 2019b). The model is displayed in Eq. 4.

FSOrSTS $=\frac{C S}{a+b(C S)}$

FS, STS, and CS are flexural strength, splitting tensile strength, and compressive strength.

a \& b are model parameters. The performance of the Eq. 4 was compared with the following models (Eq. 5, Eq. 6, and Eq. 7).

\section{(ii). Exponential Association 2 model}

The Exponential Association 2 model is also used to correlate the flexural strength with the compressive strength of cement-based mortar; the model is shown in Eq. 5 (Ojha et al. 2018; Oladoye et al. 2020).

$F S=\alpha\left(1-e^{-\beta(C S)}\right)$

FS, CS are flexural and compressive strengths, a \& $\beta$ are model parameters.

\section{(iii). DR-Hill-Zero background model}

Additionally, the DR-Hill-Zero background model is used to predict flexural and splitting tensile strengths from compressive strength, which is displayed in Eq. 6 (Kumar and Munjal 2018).

FSorSTS $=\frac{\theta(C S)^{\eta}}{K^{\eta}+(C S)^{\eta}}$

FS, STS, and CS are flexural strength, splitting tensile strength, and compressive strength. $\theta, \eta$, and $k$ are model parameters.

(iv). Power Model

The power model formula is presented in Eq. 7 (Patel et al. 2009).

FSorSTS $=\phi(C S)^{\omega}(7)$

FS, STS, and CS are flexural strength, splitting tensile strength, and compressive strength. $\varphi$ and $\omega$ and are model parameters.

\section{Performance Criteria For Model Evaluation}

The developed models are evaluated based on different assessment tools to choose the best model to predict the CS of the mortar; the following are efficiency measurements for the models: 


$$
R^{2}=1-\frac{\sum_{1}^{n}(y p-y e)^{2}}{\sum_{1}^{n}(y e-y e)^{2}}
$$

$R=\sqrt{R^{2}}$

$R M S E=\sqrt{\frac{S S E}{n}}$

$M A E=\frac{\sum_{1}^{n}|y p-y e|}{n}$

$M B E=\frac{\sum_{1}^{n}(y p-y e)}{n}$

$S I=\frac{R M S E}{-}$

$O B J=\left(\frac{n_{t r}}{n_{t o}} * \frac{R M S E_{t r}+M A E_{t r}}{R^{2}{ }_{t r}+1}\right)+\left(\frac{n_{t e}}{n_{t o}} * \frac{R M S E_{t e}+M A E_{t e}}{R_{t e}^{2}+1}\right)+\left(\frac{n_{\mathrm{val}}}{n_{t o}} * \frac{R M S E_{\mathrm{val}}+M A E_{\mathrm{val}}}{R_{\mathrm{val}}^{2}+1}\right)$

$t_{t e s t}=\sqrt{\frac{(n-1) M B E^{2}}{R M S E^{2}-M B E^{2}}}$

$U_{95}=1.96 * \sqrt{S D^{2}+R M S E^{2}}$

$\rho=\frac{S I}{1+R}$

Where $\mathrm{R}^{2}$, RMSE, MAE, MBE, SI, OBJ, t-test, $\mathrm{U}_{95}$, and $\rho$ are Coefficient of Determination, Root Mean Squared Error, Mean Absolute Error, an Average of Errors, Scatter Index, Objective, t-test, 95\% Confidence Uncertainty, and Performance Index, respectively. yp, ye, and ye are predicted compressive strength, measured compressive strength, and an average of measured compressive strength, respectively. $n$, tr, te, val. are several data in the training, testing, and validating dataset.

For all of the assessment parameters, the ideal value is zero, while the best value for $\mathrm{R}^{2}$ is 1 . Corresponding to $\mathrm{SI}$, the performance of the model is excellent, good, fair, and poor if the $\mathrm{SI}<0.1,0.1<\mathrm{SI}<0.2,0.2<\mathrm{SI}<$ 0.3, and $\mathrm{SI}>0.3$, respectively (Li et al. 2013).

\section{Analysis Of Outputs}




\subsection{Relation between predicted and measured compressive strength}

\subsubsection{MEP model}

Comparison of measured with the predicted value of CS using the MEP model is presented in Fig. 6 . The model had a good performance with $\mathrm{R}^{2}$ of $0.87,0.87$, and 0.897 for training, testing, and validating, respectively. Figure 6 (a) contained -20 and $+25 \%$ error lines in the training phase and -10 and $15 \%$ for testing and validating (Fig. $6 \mathrm{~b} \& \mathrm{c}$ ).

$C S=A+B+C+25-\frac{D-B-C-25}{D+\frac{2}{3}}-E-\frac{B+C}{F}$

$A=\frac{2\left(\frac{w}{c}\right)(F A)}{25}-15\left(\frac{w}{c}\right)^{2}$

$B=\frac{2}{15\left(t-15\left(\frac{w}{c}\right)^{2}\right)}$

$C=\frac{2(F A)}{15\left(\frac{w}{c}\right)}$

$D=\frac{225\left(\frac{w}{c}\right)^{2}}{2\left(t-15\left(\frac{w}{c}\right)^{2}\right.}$

$E=\frac{4(F A)^{2}}{375}(18 f)$

$F=225\left(\frac{w}{c}\right)^{3}$

No. of Data $=300, \mathrm{R}^{2}=0.858, \mathrm{RMSE}=4.943 \mathrm{MPa}$

\subsubsection{NLR model}

The variation of predicted compressive strength with measured compressive strength is displayed in Fig. 7. From the modeling result, it is clear w/c and curing time are affect the CS more than fly ash content. In comparison, the effect of $\mathrm{w} / \mathrm{c}$ is more significant on the compression strength of cement-mortar. The model 
is developed, and the parameters are determined using the least square method and solver technique (Mohammed et al. 2020b). The NLR model is presented in Eq. 18.

$$
C S=0.62 \times \frac{(t)^{0.273}}{\left(\frac{w}{c}\right)^{0.872}} \times(F A)^{0.208}+7.681 \times \frac{(t)^{0.235}}{\left(\frac{w}{c}\right)^{0.759}}
$$

No. of Data $=300, \mathrm{R}^{2}=0.85, \mathrm{RMSE}=5.34 \mathrm{MPa}$

\subsubsection{ANN model}

Figure 8 shows the optimal ANN network structures, the best network structure (Fig. 8) selected containing one hidden layer and six hidden neurons, with momentum, learning rate, learning time of $0.1,0.2$, and 2000, respectively. Those mentioned parameters for the network were determined by trial and error based on RMSE and MAE, as illustrated in Fig. 9. Figure 10 shows variation in predicted CS with measured CS using the training dataset and error line -20 to $+20 \%$, indicating the measurements and predictions are in this limit with $\mathrm{R}^{2}$, RMSE of 0.859 , and $5.179 \mathrm{MPa}$.

\subsubsection{M5P-tree model}

Figure 11 shows the division of the input space by the algorithm of the M5P-tree model into four linear regression functions named LM 1 and LM 4. The relationship of predicted and measured CS of the M5Ptree model showed in Fig. 12, with $\mathrm{R}^{2}$ and RMSE of 0.824 and $5.771 \mathrm{MPa}$. There are -20 to $25 \%$ error lines for the training data set and -15 to $20 \%$ for testing, and -15 to $25 \%$ for validating datasets. Figure 11 shows the pruned M5P-tree, which classified the training dataset into four parts based on the criteria shown in the figure; each part of the divided dataset resulted in a single regression model as mentioned in Eq. 3, the model parameters for the M5P-tree model are summarized in Table 3.

\subsection{Relationship between compressive, flexural, and tensile strengths}

Based on the collected data, three different models were developed to predict flexural and splitting tensile strengths from measured compressive strength using the Vipulanandan correlation model, Exponential association-2, DR-Hill-Zero background, and Power model, as illustrated in Eqs. 20 to 25. Figure 13 (a) shows the variation of FS with CS for data collected from literature and predicted FS using developed models. The residual error for predicted FS from CS ranged between $1 \mathrm{MPa}$ to $-1 \mathrm{MPa}$ is shown in Fig. 13 (b). Variation of splitting tensile strength with CS is shown in Fig. 13 (c), and the residual errors for predicted STS from CS using ranged between $0.15 \mathrm{MPa}$ to $-0.35 \mathrm{MPa}$ (Fig. 13 (d)).

\section{(i) Vipulanandan correlation model}

$F S=\frac{C S}{3.06+0.073(C S)}(20)$

No. of data $=56, \mathrm{R}^{2}=0.955, \mathrm{RMSE}=0.396 \mathrm{MPa}$ 
$S T S=\frac{C S}{5.144+0.108(C S)}(21)$

No. of data $=27, \mathrm{R}^{2}=0.981, \mathrm{RMSE}=0.115 \mathrm{MPa}$

\section{(ii) Exponential association 2}

$F S=9.446\left(1-e^{-0.032(C S)}\right)$

No. of data $=56, \mathrm{R}^{2}=0.958, \mathrm{RMSE}=0.386 \mathrm{MPa}$

\section{(iii) DR-Hill-Zero Background}

$F S=\frac{10.789(C S)^{1.293}}{26.574^{1.293}+(C S)^{1.293}}$

No. of Data $=56, \mathrm{R}^{2}=0.958, \mathrm{RMSE}=0.382 \mathrm{MPa}$

$S T S=\frac{71.87(C S)^{0.741}}{1598.864^{0.741}+(C S)^{0.741}}$

No. of Data $=27, \mathrm{R}^{2}=0.982, \mathrm{RMSE}=0.11 \mathrm{MPa}$.

\section{(iv). Power Model}

$S T S=0.316(C S)^{0.714}(25)$

No. of Data $=27, \mathrm{R}^{2}=0.982, \mathrm{RMSE}=0.11 \mathrm{MPa}$.

Based on the $\mathrm{R}^{2}$ and RMSE, the DR-Hill-Zero background model is better than other models for predicting flexural strength from compressive strength; on the other hand, the best model for correlation of splitting tensile strength with compressive strength is DR-Hill-Zero background and Power Models.

\subsection{Model Evaluations}

The proposed models are compared according to the relationship between predicted and measured CS for testing data set; the MEP model had less variation; the plotted data are near the $\mathrm{Y}=\mathrm{X}$ line, which indicates a minor error in predicted values, as shown in Fig. 14 (a). Furthermore, the maximum and minimum residual errors for the MEP model were -19 and $18 \mathrm{MPa}$. Residual error of NLR, ANN, and M5P-tree model was - 12 to $14 \mathrm{MPa},-14$ to $14 \mathrm{MPa}$, and -21 to $19 \mathrm{MPa}$, respectively. The residual error indicates better performance of the NLR model than other developed models, as shown in Fig. 14 (b).

The SI value of the MEP model, NLR, ANN, and M5P-tree model for the training dataset was $0.148,0.16$, 0.155 , and 0.173 . When comparing SI value for validating datasets, the SI value for the MEP model is less than NLR, ANN, and M5P-tree model by 8,6 , and $16.5 \%$, respectively. For the testing dataset, the SI value of 
the MEP model is equal to 0.159 and less than ANN, and M5P-tree model by 10 and $5 \%$, and more significant than the NLR model by $5 \%$, as shown in Fig. 15 (a).

The comparison of developed models based on MAE is presented in Fig. 15 (b). The MAE for MEP models is less than the MAE of other developed models for training and validating datasets; however, the MAE of MEP model value for testing is less than ANN, and M5P- tree model by 8 and $4 \%$, and greater than the NLR model by $6 \%$.

The OBJ values for the proposed models are also evaluated; the OBJ for the MEP model is less than NLR, ANN, and M5P-tree models by 7, 6, and 14, as displayed in Fig. 16 (a).

The t-test and $U_{95}$ values comparison for the developed models is illustrated in Fig. 16 (b). as can be seen from the figure, the uncertainty of the predicted compressive strength for $95 \%$ confidence level of MEP model is less than ANN and M5P-tree models by 2 and $6 \%$, and greater than NLR model by $4 \%$. However, the t-test value of the MEP model is less than other developed models. The t-test value results in a probability of accepting or rejecting the null hypothesis. The larger t-test value indicates a significant difference in the measured and predicted CS of the cement mortar.

Also, the performance index for the MEP model was less than other developed models for training and validating data. At the same time, it is greater than the NLR model in testing the data set by $4 \%$, as presented in Fig. 17 (a).

The box plot for actual and predicted CS is drawn as shown in Fig. 18 (a, b \& c). The boxplot for the MEP model had the same pattern for the minimum and maximum CS values, Mean and median. According to the box plot MEP model is better than other developed models.

Summary of model evaluation for $\mathrm{R}^{2}, \mathrm{RMSE}$, and MAE of the developed models is presented in Table 4 .

Table 4

Summary of developed models performance

\begin{tabular}{|c|c|c|c|c|c|c|c|c|c|c|c|}
\hline \multirow[t]{2}{*}{ Models } & \multirow{2}{*}{$\begin{array}{l}\text { Fig. } \\
\text { No. }\end{array}$} & \multirow{2}{*}{$\begin{array}{l}\text { Eq. } \\
\text { No. }\end{array}$} & \multicolumn{3}{|c|}{ Training datasets } & \multicolumn{3}{|c|}{ Testing datasets } & \multicolumn{3}{|c|}{ Validating datasets } \\
\hline & & & $\mathrm{R}^{2}$ & $\begin{array}{l}\text { RMSE } \\
\text { (MPa) }\end{array}$ & $\begin{array}{l}\mathrm{MAE} \\
(\mathrm{MPa})\end{array}$ & $\mathrm{R}^{2}$ & $\begin{array}{l}\text { RMSE } \\
\text { (MPa) }\end{array}$ & $\begin{array}{l}\mathrm{MAE} \\
(\mathrm{MPa})\end{array}$ & $\mathbf{R}^{2}$ & $\begin{array}{l}\text { RMSE } \\
\text { (MPa) }\end{array}$ & $\begin{array}{l}\mathrm{MAE} \\
(\mathrm{MPa})\end{array}$ \\
\hline MEP & 6 & 17 & 0.87 & 4.86 & 3.23 & 0.88 & 3.88 & 2.77 & 0.897 & 4.72 & 3.35 \\
\hline NLR & 7 & 18 & 0.84 & 5.39 & 3.83 & 0.85 & 4.28 & 3.35 & 0.81 & 6.35 & 4.95 \\
\hline ANN & 10 & - & 0.9 & 4.23 & 2.89 & 0.86 & 4.15 & 3.03 & 0.88 & 5.07 & 3.76 \\
\hline $\begin{array}{l}\text { M5P- } \\
\text { tree }\end{array}$ & 12 & 3 & 0.85 & 5.21 & 3.8 & 0.81 & 4.77 & 3.47 & 0.81 & 6.23 & 4.53 \\
\hline
\end{tabular}

\subsection{Sensitivity evaluation}


The most influential parameter on the compressive strength of cement-based mortar modified with fly ash is determined using the MEP model. Every time a single input parameter is removed from the training dataset, regression is run again in the process. MAE for the model is recorded, the trial with maximum MAE (MPa) and RMSE (MPa) is chosen, and the trials ranked according to the recorded MAE the more sensitive variable in predicting the compressive strength of cement mortar modified with fly ash is the removed parameter from the trial with the highest MAE. Based on the sensitivity analysis, the most influential parameter is the curing time of the tested samples, as summarized in Table 5.

Table 5

Sensitivity analysis for the model parameters using MEP model

\begin{tabular}{|llllll|}
\hline No. & Combination & Removed Parameter & RMSE (MPa) & MAE (MPa) & Ranking \\
\hline 1 & w/c, t, FA & - & 4.943 & 3.74 & - \\
\hline 2 & t, FA & w/c & 10.75 & 7.35 & 2 \\
\hline 3 & w/c, FA & t & 11.80 & 9.20 & 1 \\
\hline 4 & w/c, t & FA & 5.35 & 4.10 & 3 \\
\hline
\end{tabular}

\section{Conclusions}

Accurate models can be developed using different soft computing techniques; in this study, four different approaches were used to establish a reliable model for the prediction of compressive strength of cement mortar modified with fly ash; the followings are the main conclusion:

1. Based on the collected data from literature maximum percentage of fly ash is $55 \%, \mathrm{w} / \mathrm{c}$ was ranged from 0.24 to 1.2 . The addition of fly ash to cement mortar increased the compressive strength for the same mixture and $\mathrm{w} / \mathrm{c}$.

2. SI for the MEP model is less than NLR, ANN, and M5P-tree models in training and validating data set; on the other hand, the SI for MEP is more than the NLR model by $5 \%$. The objective value for the MEP model is less than other developed models. $95 \%$ Uncertainty $\left(\mathrm{U}_{95}\right)$ value for MEP is smaller than ANN and M5P-tree models. Nevertheless, its $U_{95}$ value is greater than the $U_{95}$ of the NLR model by $4 \%$. $t$-test value for the MEP model is less than other developed models.

3. The performance index of the MEP model for training and the validating dataset is less than other developed models.

4. Based on the box plot for actual and predicted compressive strength, the MEP model predictions had the same arrangement as real compressive strength compared to other developed models in maximum, minimum, mean, and median.

5. According to the statistical evaluation tools, the MEP model is better than NLR, ANN, and M5P-tree models for compressive strength prediction. It has less scatter in predicted compressive strength compared 
with measured compressive strength.

6. Depending on the sensitivity evaluation result, the curing time of the sample is the most influential parameter on the compressive strength of cement mortar modified with fly ash.

7. Reliable nonlinear models were used to predict the splitting tensile strength and the flexure strength of cement mortar modified with FA with a minimal prediction error.

\section{Recommendation}

Detailed investigations on fly ash-based geopolymer concrete's fresh and mechanical properties can be found in the literature. However, studies which are focused on the other properties of this composite are still limited. For this composite to be acceptable by the construction industry, some durability properties such as water permeability, gas permeability, chloride resistance, fatigue performance, and freeze-thaw resistance should be examined comprehensively.

\section{Declarations}

\section{Author Declarations}

We wish to draw the attention of the Editor to the following facts, which may be considered as potential conflicts of interest and to significant financial contributions to this work. [OR] We wish to confirm that there are no known conflicts of interest associated with this publication, and there has been no significant financial support for this work that could have influenced its outcome. We confirm that the manuscript has been read and approved by all named authors and that there are no other persons who satisfied the criteria for authorship but are not listed. We further confirm that all have approved the order of authors listed in the manuscript of us. We confirm that we have given due consideration to the protection of intellectual property associated with this work and that there are no impediments to publication, including the timing of publication, with respect to intellectual property. In so doing, we confirm that we have followed the regulations of our institutions concerning intellectual property. We further confirm that any aspect of the work covered in this manuscript that has involved either experimental animals or human patients has been conducted with the ethical approval of all relevant bodies and that such approvals are acknowledged within the manuscript. We understand that the Corresponding Author is the sole contact for the Editorial process (including Editorial Manager and direct communications with the office). They are responsible for communicating with the other authors about progress, submissions of revisions, and final approval of proofs. We confirm that we have provided a current, correct email address accessible by the Corresponding Author.

\section{Consent for publication}

I (Ahmed S. Mohammed) hereby declare that I participated in this study and the manuscript's development (Implementing the Multi Expression Programming, Nonlinear Regression, Artificial Neural Network, and 
M5P-Tree Models to Predict the Long-Term of Compressive Strength of Cement- Mortar Modified with Fly Ash ). I have read the final version and consent for the article to be published in this Journal.

\section{Availability of data and materials}

The data supporting the conclusions of this article are included with the article.

\section{Competing interests}

The authors declare that they have no competing interests.

\section{Funding}

This work had no finding.

\section{Authors' contributions}

Aso and Ahmed S. Mohammed are collecting data, planning, and writing. Aso, results, and analysis. Aso and Ahmed did the conclusions and editing.

\section{Acknowledgment}

The University of Sulaimani, College of Engineering, supported this work.

\section{Ethics approval and consent to participate}

Not applicable

\section{References}

1. Abed ZM (2018) The effect of using lightweight aggregate on some properties of cement mortar. Iraqi Journal of Civil Engineering 12(1):1-9

2. Aho AV, Lam MS, Sethi R, Ullman JD (2020) Compilers: principles, techniques and tools

3. Alwash JJH (2013) Use of rice husk ash in cement mortar. Journal of University of Babylon 21(2):582590

4. Apostolopoulou M, Armaghani DJ, Bakolas A, Douvika MG, Moropoulou A, Asteris PG (2019) Compressive strength of natural hydraulic lime mortars using soft computing techniques. Procedia Structural Integrity 17:914-923. https://doi.org/10.1016/j.prostr.2019.08.122

5. Armaghani DJ, Asteris PG (2021) A comparative study of ANN and ANFIS models for the prediction of cement-based mortar materials compressive strength. Neural Comput Appl 33(9):4501-4532. https://doi.org/10.1007/s00521-020-05244-4

6. Baert G, Hoste S, De Schutter G, De Belie N (2008) Reactivity of fly ash in cement paste studied by means of thermogravimetry and isothermal calorimetry. J Therm Anal Calorim 94(2):485-492. https://doi.org/10.1007/s10973-007-8787-z 
7. Biricik H, Sarier N (2014) Comparative study of the characteristics of nano silica-, silica fume-and fly ash-incorporated cement mortars. Materials Research 17:570-582. https://doi.org/10.1590/S151614392014005000054

8. Brameier M, Banzhaf W (2001) A comparison of linear genetic programming and neural networks in medical data mining. IEEE Trans Evol Comput 5(1):17-26. https://doi.org/10.1109/4235.910462

9. Bumrongjaroen W, Muller I, Schweitzer J, Livingston RA (2007) Application of glass corrosion tests to the reactivity of fly ash. World of Coal Ash, Northern Kentucky, USA

10. Burhan L, Ghafor K, Mohammed A (2020) 2020). Testing and evaluation of flowability, viscosity and long-term compressive strength of cement modified with polymeric admixture WR superplasticizer. 012066

11. Chindaprasirt P, Homwuttiwong S, Sirivivatnanon V (2004) Influence of fly ash fineness on strength, drying shrinkage and sulfate resistance of blended cement mortar. Cem Concr Res 34(7):1087-1092. https://doi.org/10.1016/j.cemconres.2003.11.021

12. Chindaprasirt P, Rukzon S, Sirivivatnanon V (2008) Resistance to chloride penetration of blended Portland cement mortar containing palm oil fuel ash, rice husk ash and fly ash. Constr Build Mater 22(5):932-938. https://doi.org/10.1016/j.conbuildmat.2006.12.001

13. Cho YK, Jung SH, Choi YC (2019) Effects of chemical composition of fly ash on compressive strength of fly ash cement mortar. Constr Build Mater 204:255-264.

https://doi.org/10.1016/j.conbuildmat.2019.01.208

14. Cramer NL (1985) A representation for the adaptive generation of simple sequential programs. In proceedings of an International Conference on Genetic Algorithms and the Applications, 183-187

15. De Weerdt K, Haha MB, Le Saout G, Kjellsen KO, Justnes H, Lothenbach B (2011) Hydration mechanisms of ternary Portland cements containing limestone powder and fly ash. Cem Concr Res 41(3):279-291. https://doi.org/10.1016/j.cemconres.2010.11.014

16. Demir İ, Güzelkücük S, Sevim Ö (2018) Effects of sulfate on cement mortar with hybrid pozzolan substitution. Engineering Science and Technology, an International Journal 21(3):275-283. https://doi.org/10.1016/j.jestch.2018.04.009

17. Demircan E, Harendra S, Vipulanandan C (2011) Artificial neural network and nonlinear models for gelling time and maximum curing temperature rise in polymer grouts. J Mater Civ Eng 23(4):372-377. https://doi.org/10.1061/(ASCE)MT.1943-5533.0000172

18. Fraay ALA, Bijen JM, De Haan YM (1989) The reaction of fly ash in concrete a critical examination. Cem Concr Res 19(2):235-246. https://doi.org/10.1016/0008-8846(89)90088-4

19. Gartner E (2004) Industrially interesting approaches to "low-CO2" cements. Cem Concr Res 34(9):1489-1498. https://doi.org/10.1016/j.cemconres.2004.01.021

20. Giergiczny Z (2004) Effect of some additives on the reactions in fly ash-Ca (OH) 2 system. J Therm Anal Calorim 76(3):747-754. https://doi.org/10.1023/B:JTAN.0000032259.80031.b2

21. Handley S (1994) On the use of a directed acyclic graph to represent a population of computer programs.154-159 
22. Hassett DJ, Eylands KE (1997) Heat of hydration of fly ash as a predictive tool. Fuel 76(8):807-809. https://doi.org/10.1016/S0016-2361(97)00058-6

23. Holland JH (1992) Adaptation in natural and artificial systems: an introductory analysis with applications to biology, control, and artificial intelligence. MIT press

24. Jung S, Kwon S-J (2013) Engineering properties of cement mortar with pond ash in South Korea as construction materials: from waste to concrete. Open Engineering 3(3):522-533. https://doi.org/10.2478/s13531-012-0068-3

25. Koza JR, Koza JR (1992) Genetic programming: on the programming of computers by means of natural selection, vol 1. MIT press

26. Kumar KM, Munjal ML (2018) Direct estimation and experimental validation of the acoustic source characteristics of two-cylinder naturally aspirated diesel engine exhaust system. Appl Acoust 135:7084. https://doi.org/10.1016/j.apacoust.2018.01.022

27. Li M-F, Tang X-P, Wu W, Liu H-B (2013) General models for estimating daily global solar radiation for different solar radiation zones in mainland China. Energy Conv Manag 70:139-148. https://doi.org/10.1016/j.enconman.2013.03.004

28. Mahmood W, Mohammed A (2019) New Vipulanandan pq model for particle size distribution and groutability limits for sandy soils. J Test Eval 48(5):3695-3712. https://doi.org/10.1520/JTE20180606

29. Marangu JM (2020) Prediction of compressive strength of calcined clay based cement mortars using support vector machine and artificial neural network techniques. Journal of Sustainable Construction Materials and Technologies 5(1):392-398

30. Mishra S, Deodhar SV (2013) Effect of rice husk ash on cement mortar and concrete. New Building Materials and Construction World 13:224-227

31. Mohammed A, Mahmood W (2018a) Statistical variations and new correlation models to predict the mechanical behavior and ultimate shear strength of gypsum rock. Open Engineering 8(1):213-226. https://doi.org/10.1515/eng-2018-0026

32. Mohammed A, Mahmood W (2018b) Vipulanandan failure models to predict the tensile strength, compressive modulus, fracture toughness and ultimate shear strength of calcium rocks. Int J Geotech Eng. https://doi.org/10.1080/19386362.2018.1468663

33. Mohammed A, Mahmood W, Ghafor K (2020a) Shear stress limit, rheological properties and compressive strength of cement-based grout modified with polymers. Journal of Building Pathology and Rehabilitation 5(1):1-17

34. Mohammed A, Rafiq S, Sihag P, Kurda R, Mahmood W (2020b) Soft computing techniques: systematic multiscale models to predict the compressive strength of HVFA concrete based on mix proportions and curing times. Journal of Building Engineering 101851. https://doi.org/10.1016/j.jobe.2020.101851

35. Mohammed AS (2017) Effect of temperature on the rheological properties with shear stress limit of iron oxide nanoparticle modified bentonite drilling muds. Egyptian J Petroleum 26(3):791-802. https://doi.org/10.1016/j.ejpe.2016.10.018 
36. Mohammed AS (2018) Vipulanandan model for the rheological properties with ultimate shear stress of oil well cement modified with nanoclay. Egyptian J Petroleum 27(3):335-347.

https://doi.org/10.1016/j.ejpe.2017.05.007

37. Mousavi SM, Gandomi AH, Alavi AH, Vesalimahmood M (2010) Modeling of compressive strength of HPC mixes using a combined algorithm of genetic programming and orthogonal least squares.

Structural engineering and mechanics: An international journal 36(2):225-241.

https://doi.org/10.12989/sem.2010.36.2.225

38. Ojha RP, Verma CL, Denis DM (2018) Estimating unsaturated hydraulic conductivity function of sodic and normal soils using point source field dripper method. J Soil Water Conserv 17(1):34-40.

https://doi.org/http://dx.doi.org/10.5958/2455-7145.2018.00005.X

39. Oladoye AO, Ige PO, Baurwa N, Onilude QA, Animashaun ZT (2020) Slenderness coefficient models for tree species in Omo biosphere reserve, South-western Nigeria

40. Oltean M, Dumitrescu D (2002) Multi expression programming. Journal of Genetic Programming and Evolvable Machines, Kluwer, second tour of review. https://doi.org/10.13140/RG.2.2.17611.52003

41. Otsuka T, Mori S, Ishikawa M, Sakai E (2009) Relation between mineral compositions of fly ash and its pozzolanic reaction. Cem Sci Concr Technol 63(1):16-21

42. Patel KB, Patel BR, Madhusudan MP (2009) 2009). Irrigation scheduling through water production function for rabi brinjal with surface and drip irrigation methods. 557-561

43. Peter C (2005) Hewlett, Lea's Chemistry of Cement and Concrete. John Wiley and Sons Inc 605:1015810012

44. Puertas $F$, Amat T, Fernández-Jiménez A, Vázquez T (2003) Mechanical and durable behaviour of alkaline cement mortars reinforced with polypropylene fibres. Cem Concr Res 33(12):2031-2036. https://doi.org/10.1016/S0008-8846(03)00222-9

45. Qadir W, Ghafor K, Mohammed A (2019a) Characterizing and modeling the mechanical properties of the cement mortar modified with fly ash for various water-to-cement ratios and curing times. Advances in Civil Engineering, 2019. https://doi.org/10.1155/2019/7013908

46. Qadir W, Ghafor K, Mohammed A (2019b) Evaluation the effect of lime on the plastic and hardened properties of cement mortar and quantified using Vipulanandan model. Open Engineering 9(1):468480. https://doi.org/10.1515/eng-2019-0055

47. Quinlan JR (1992) 1992). Learning with continuous classes. In 5th Australian joint conference on artificial intelligence, 343-348

48. Rahhal V, Talero R (2004) Influence of two different fly ashes on the hydration of portland cements. J Therm Anal Calorim 78(1):191-205. https://doi.org/10.1023/b:jtan.0000042167.46181.17

49. Rai B, Kumar S, Satish K (2014) Effect of fly ash on mortar mixes with quarry dust as fine aggregate. Advances in materials Science and Engineering, 2014. https://doi.org/10.1155/2014/626425

50. Sakai E, Miyahara S, Ohsawa S, Lee S-H, Daimon M (2005) Hydration of fly ash cement. Cem Concr Res 35(6):1135-1140. https://doi.org/10.1016/j.cemconres.2004.09.008 
51. Sasiekalaa K, Malathy R (2012) Behaviour of mortar containing silica fume and fly ash. J Ind Pollut Control 28:1-7

52. Shah MI, Amin MN, Khan K, Niazi MSK, Aslam F, Alyousef R, Javed MF, Mosavi A (2021) Performance Evaluation of Soft Computing for Modeling the Strength Properties of Waste Substitute Green Concrete. Sustainability 13(5):2867. https://doi.org/10.3390/su13052867

53. Sihag P, Jain P, Kumar M (2018) Modelling of impact of water quality on recharging rate of storm water filter system using various kernel function based regression. Modeling earth systems and environment 4(1):61-68. https://doi.org/10.1007/s40808-017-0410-0

54. Suba S (2009) Prediction of mechanical properties of cement containing class $C$ fly ash by using artificial neural network and regression technique. Scientific research and essays 4(4):289-297

55. Tan Z, De Schutter G, Ye G, Gao Y (2013) The effect of limestone powder addition on strength of slag blended cement. Concrete under Severe Conditions: Environment and Loading (CONSEC-2013), 2, 18881898

56. Thongsanitgarn P, Wongkeo W, Sinthupinyo S, Chaipanich A (2012) Effect of limestone powders on compressive strength and setting time of Portland-limestone cement pastes.322-326

57. Türkel S, Altuntaş Y (2009) The effect of limestone powder, fly ash and silica fume on the properties of self-compacting repair mortars. Sadhana 34(2):331-343

58. Vipulanandan C, Mohammed A (2019) Magnetic field strength and temperature effects on the behavior of oil well cement slurry modified with iron oxide nanoparticles and quantified with vipulanandan models. J Test Eval 48(6):4516-4537. https://doi.org/10.1520/JTE20180107

59. Vipulanandan C, Mohammed A, Ganpatye AS (2018) Smart cement performance enhancement with NanoAl2O3 for real time monitoring applications using Vipulanandan models

60. Vipulanandan C, Mohammed AS (2014) Hyperbolic rheological model with shear stress limit for acrylamide polymer modified bentonite drilling muds. J Petrol Sci Eng 122:38-47. https://doi.org/10.1016/j.petrol.2014.08.004

61. Wang Y, Witten IH (1996) Induction of model trees for predicting continuous classes. https://hdl.handle.net/10289/1183

62. Wong YL, Lam L, Poon CS, Zhou FP (1999) Properties of fly ash-modified cement mortar-aggregate interfaces. Cem Concr Res 29(12):1905-1913. https://doi.org/10.1016/S0008-8846(99)00189-1

63. Xu A, Sarkar SL, Nilsson L-O (1993) Effect of fly ash on the microstructure of cement mortar. Mater Struct 26(7):414-424. https://doi.org/10.1007/BF02472942

64. Yerramala A, Desai B (2012) Influence of fly ash replacement on strength properties of cement mortar. International Journal of Engineering Science and Technology 4(8):3657-3665

\section{Figures}




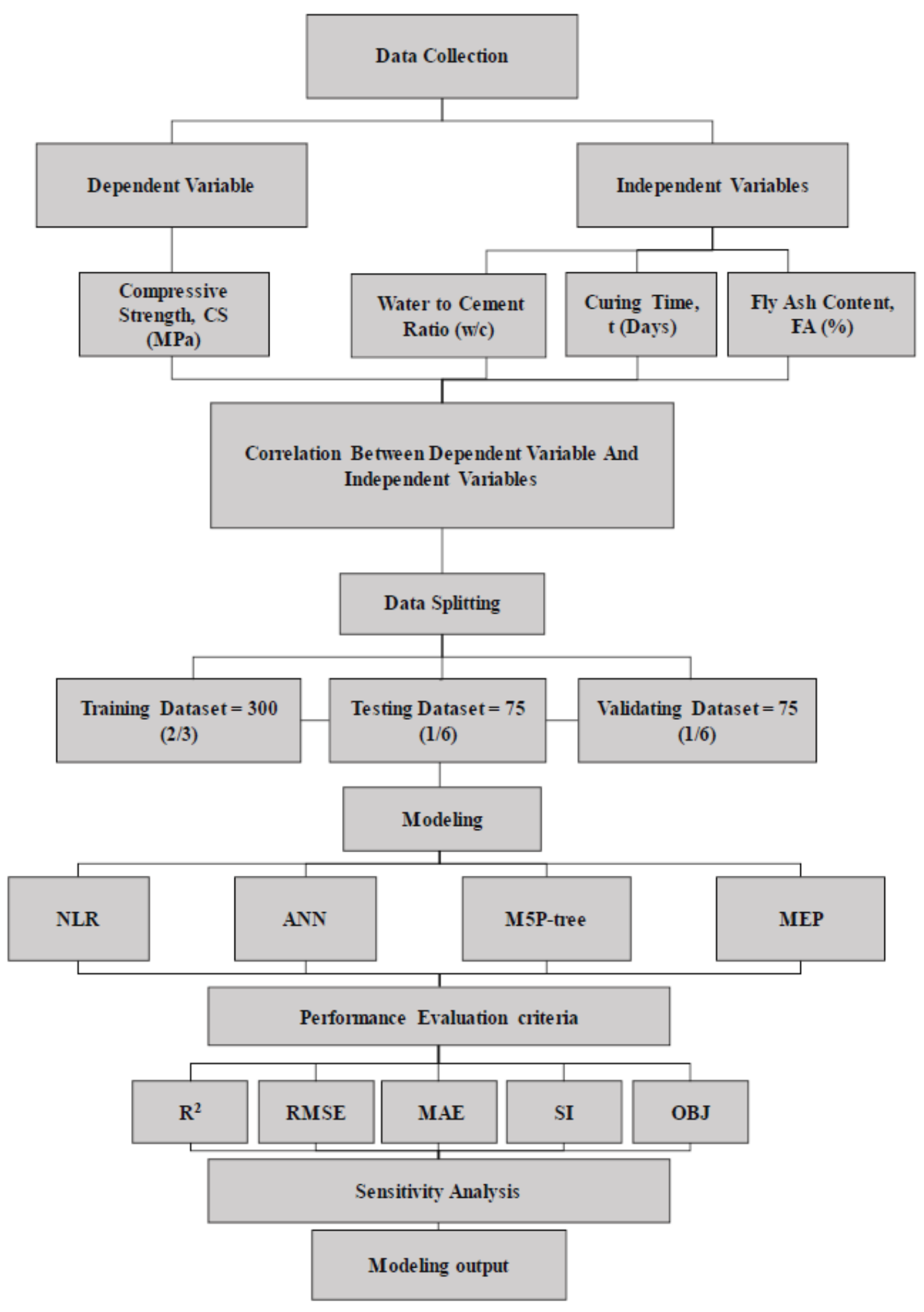

Figure 1

Methodology flowchart of the current study 

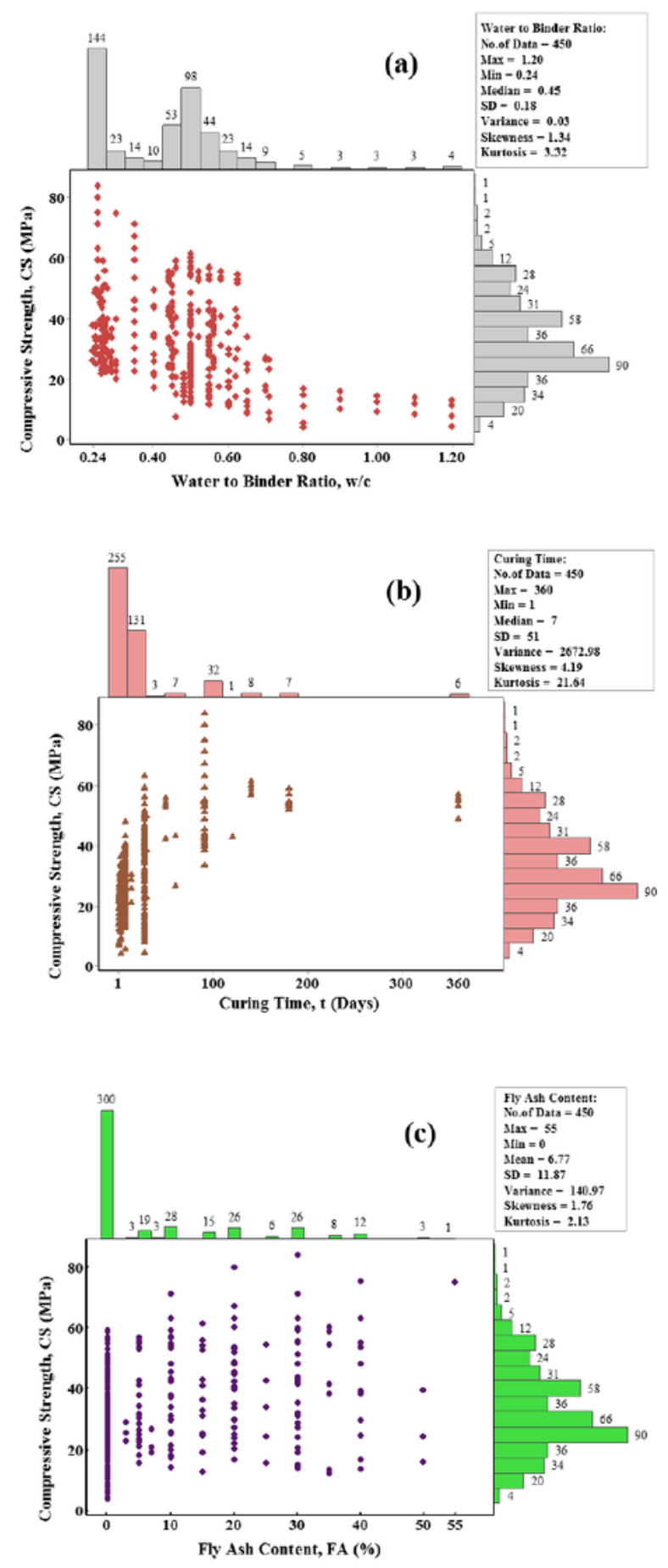

\section{Figure 2}

Marginal plot for (a) compressive strength (CS) with water to cement ratio, (b) CS with curing time, and (c) CS with fly ash content 

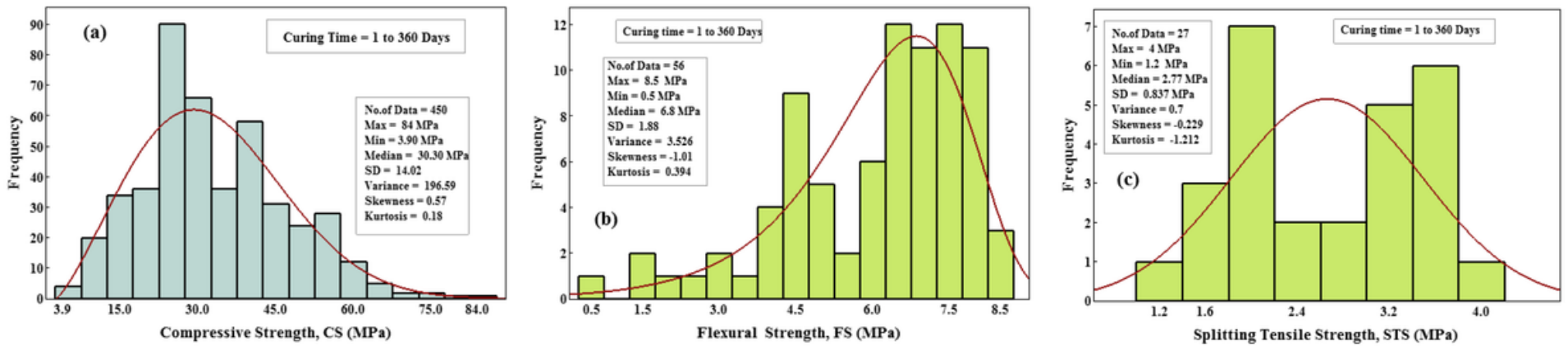

Figure 3

Histogram for (a) compressive strength, (b) flexural strength, and (c) splitting tensile strength for fly ash modified cement mortar from 1 to 360 days of curing

$\mathbf{w} / \mathbf{c}$

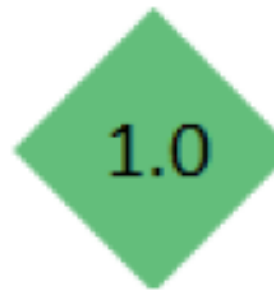

0.191

\section{0}

$0.210<0.541$

FA

0.082

0.210

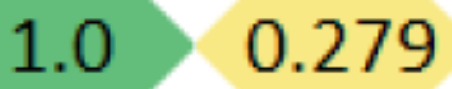

CS
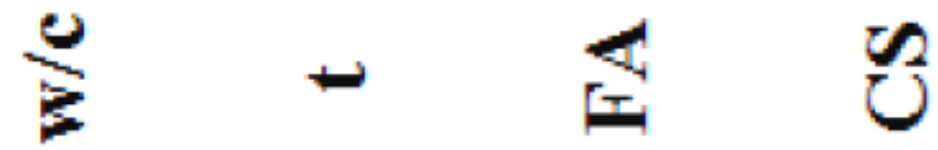

Figure 4 


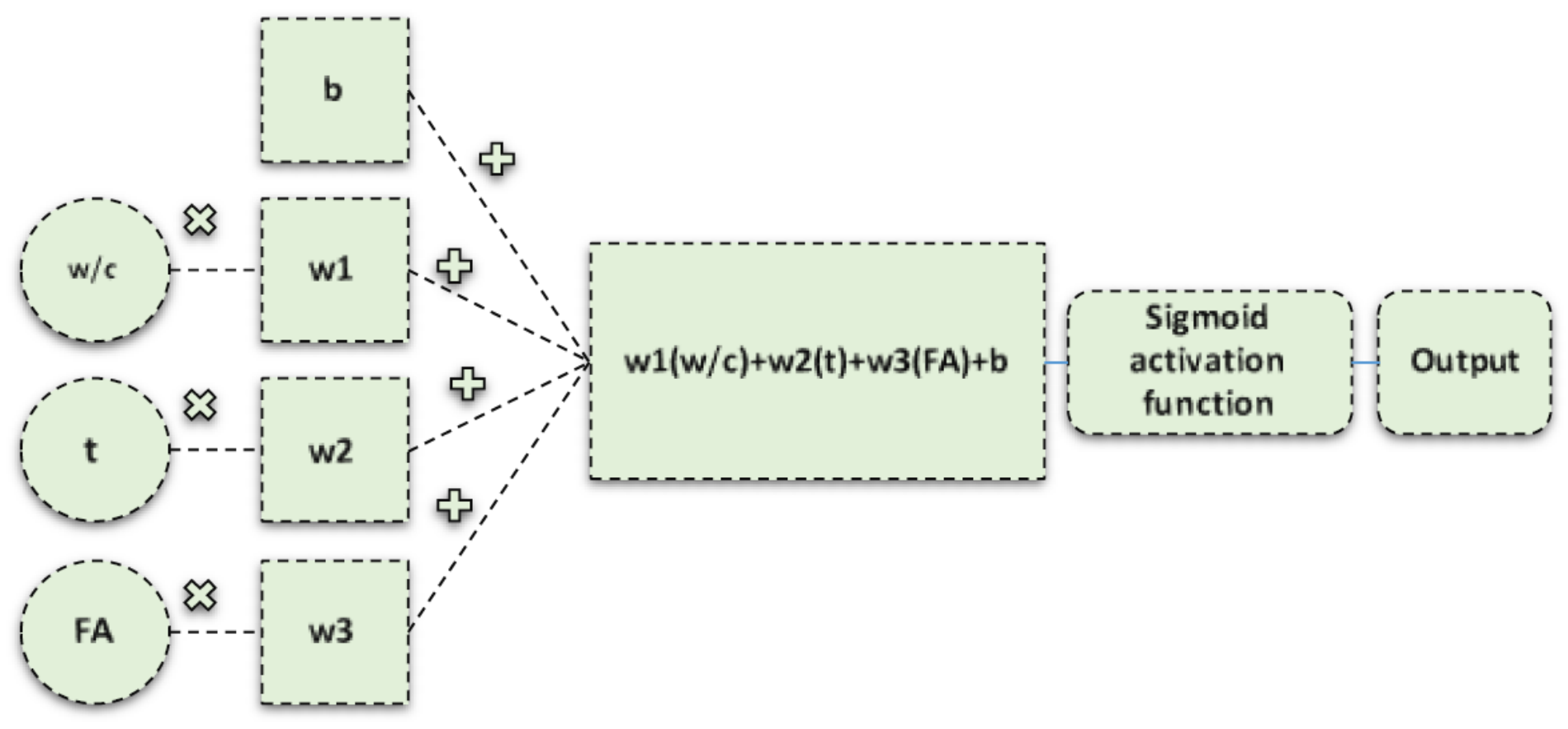

Figure 5

Typical procedure for output of ANN network in a single node
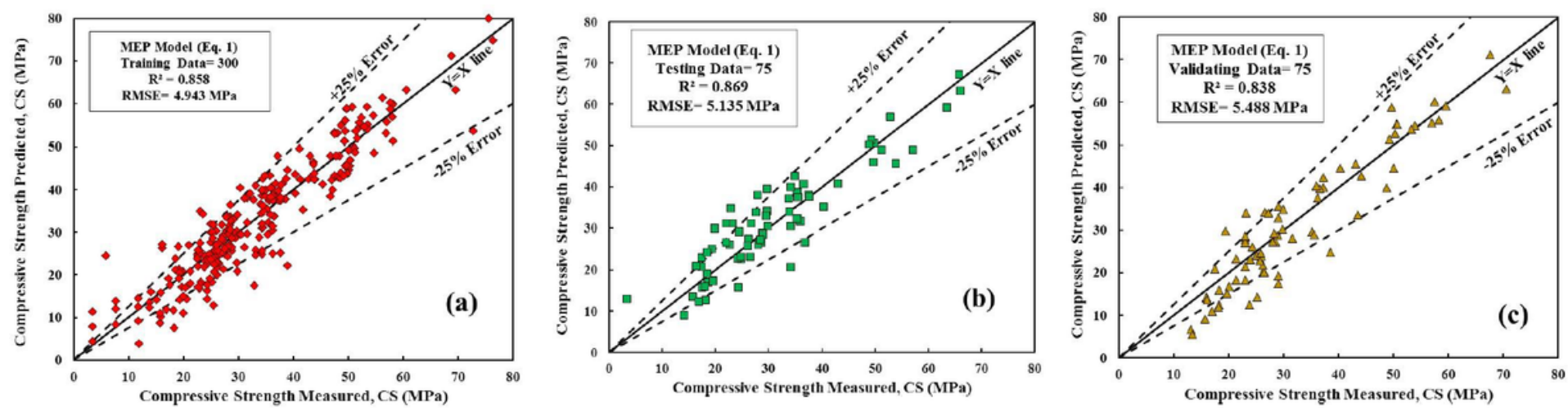

Figure 6

Variation of CS Predicted with CS Measured using MEP model (a) training data, (b) testing data, and (c) validating data 

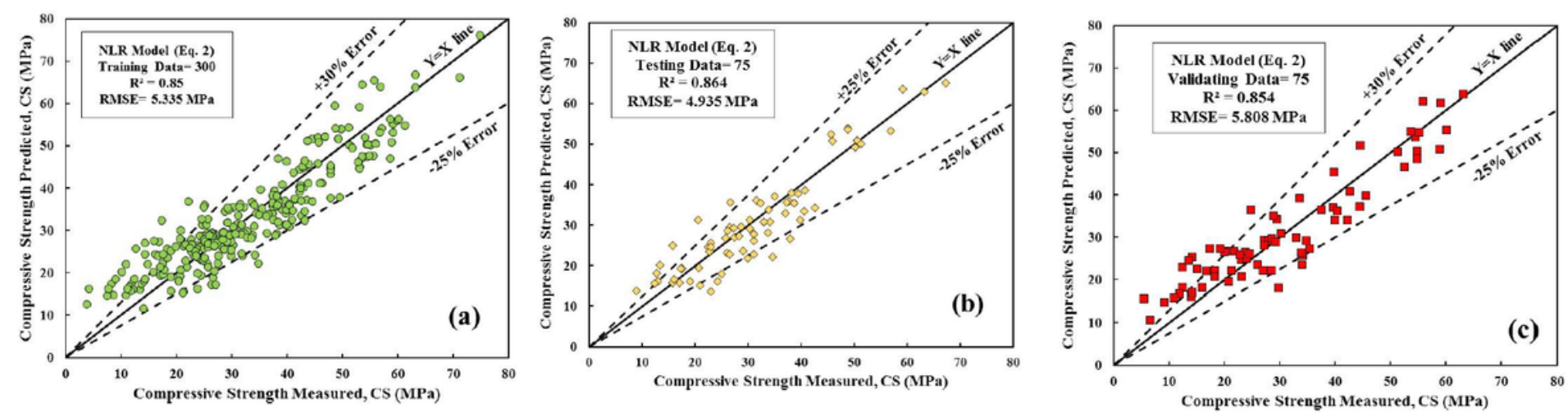

Figure 7

Variation of CS Predicted with CS Measured using NLR model (a) training data, (b) testing data, and (c) validating data 

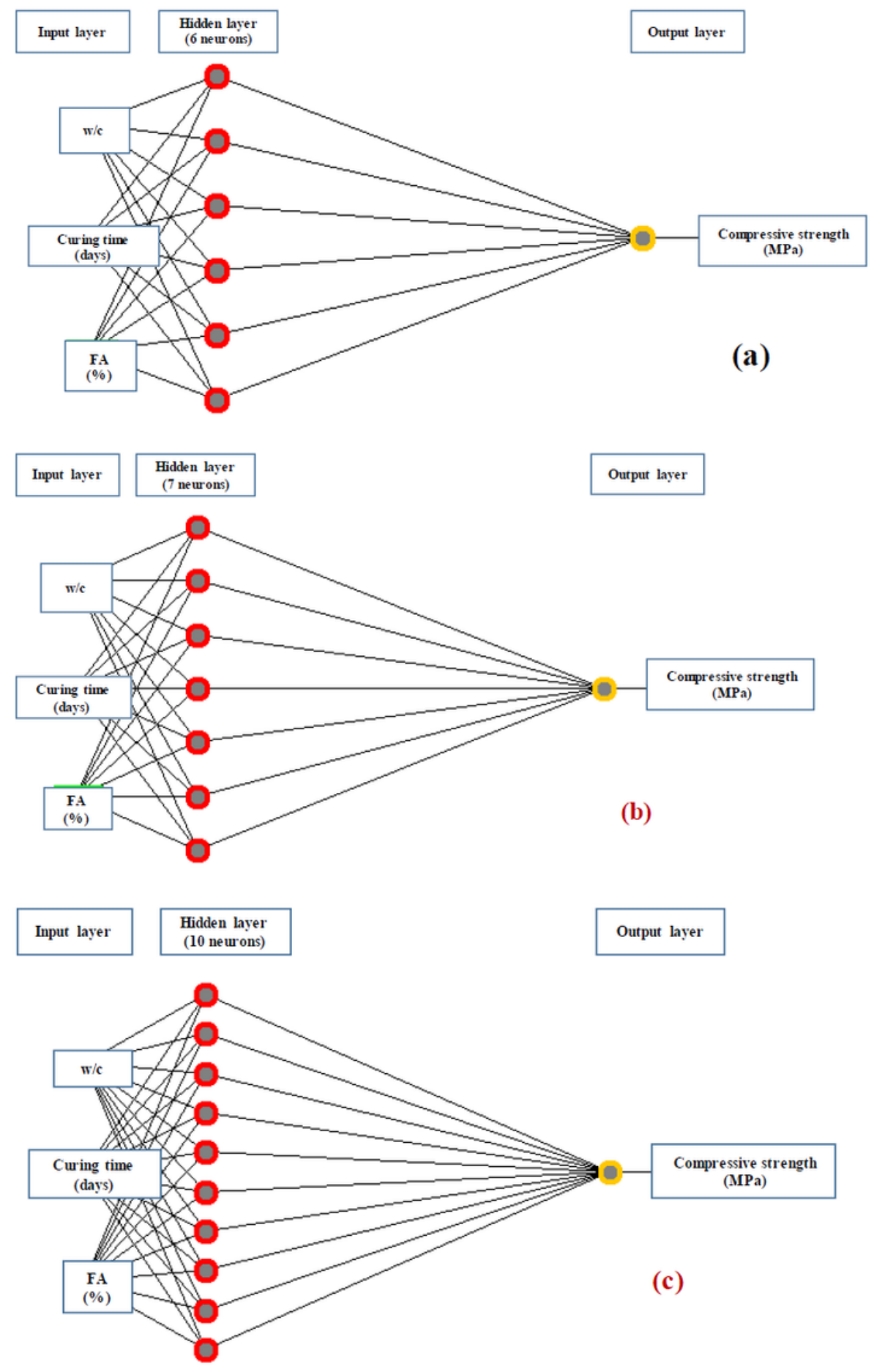

\section{Figure 8}

Optimal ANN network structures (a) one hidden layer and 6 hidden neurons, (b) one hidden layer and 7 hidden neurons, and (c) one hidden layer and 10 hidden neurons 


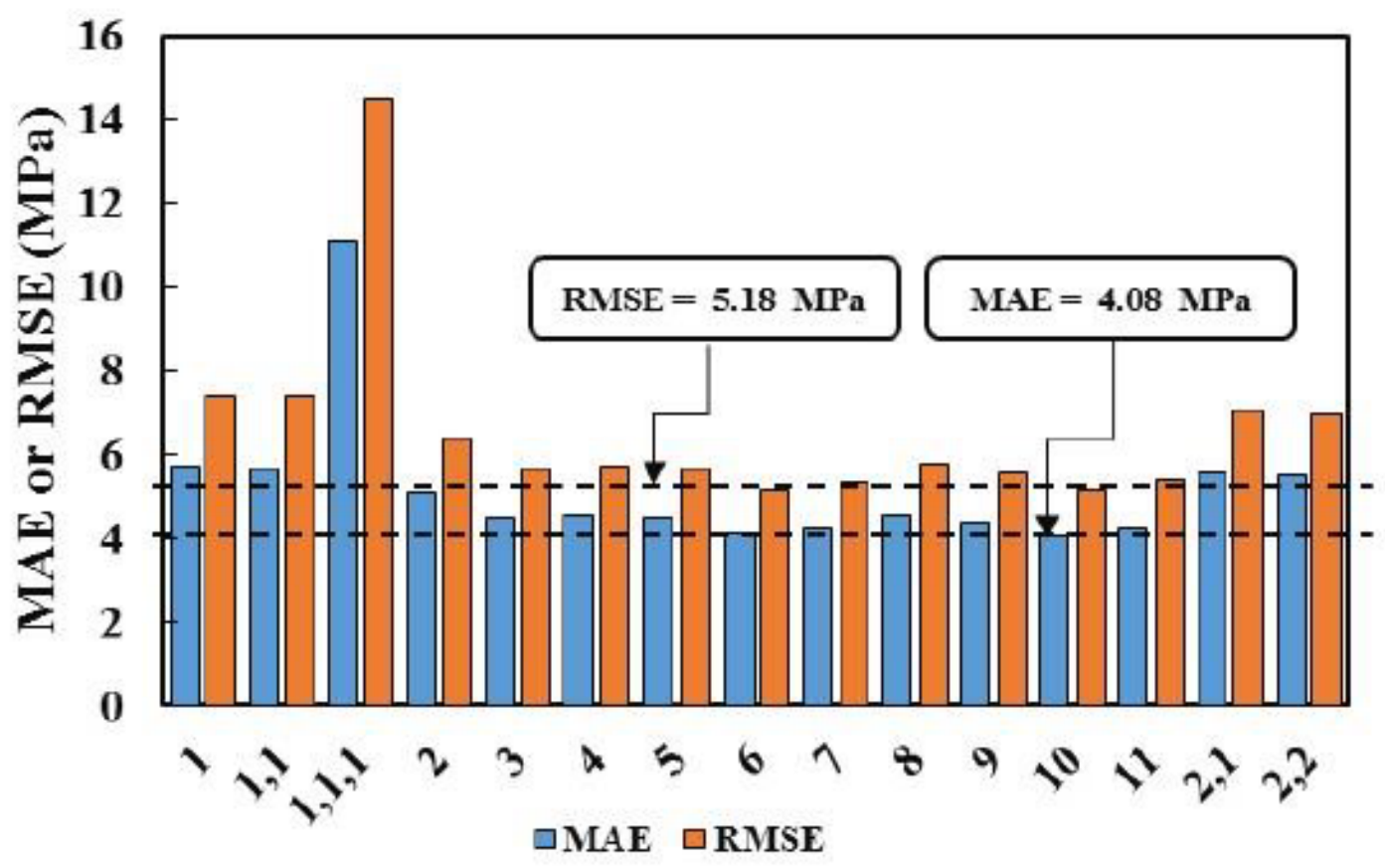

Figure 9

Optimal ANN network selection based on RMSE and MAE 

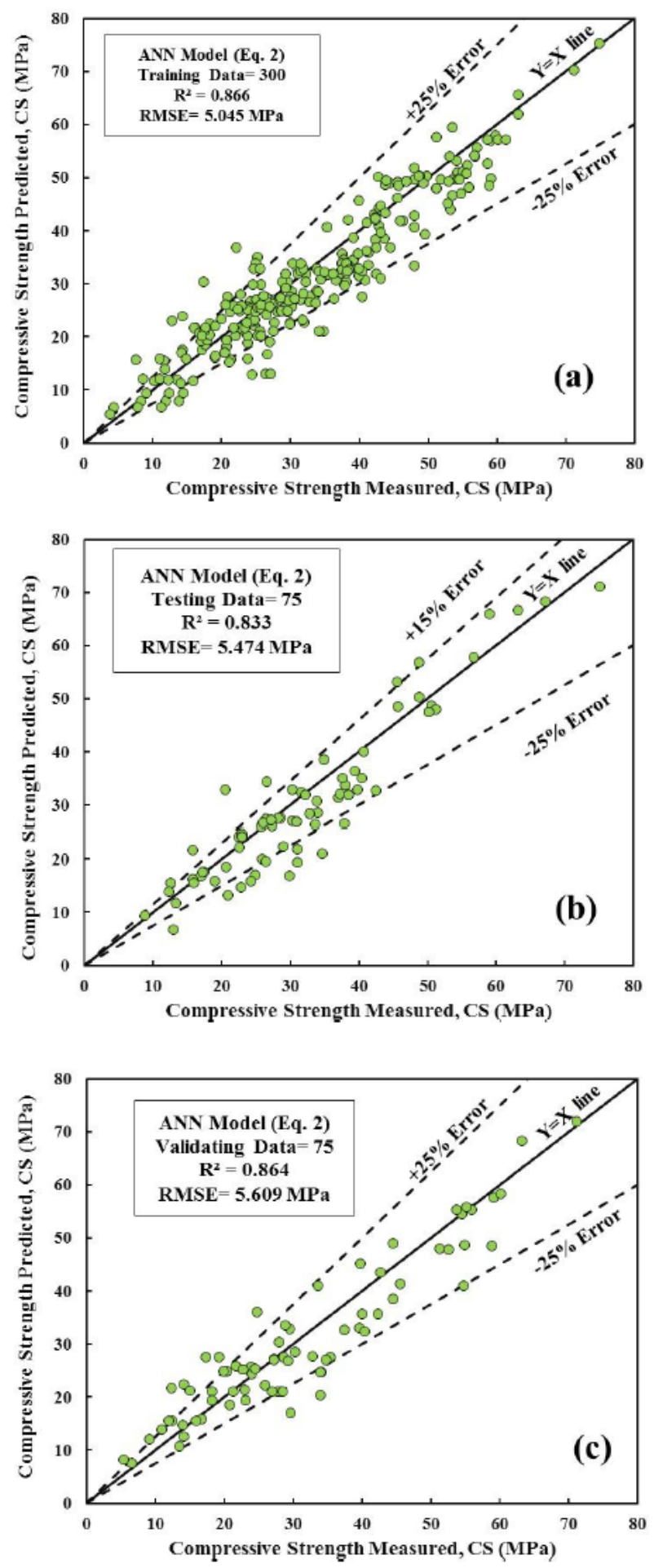

\section{Figure 10}

Variation of CS Predicted with CS Measured using ANN model (a) training data, (b) testing data, and (c) validating data 


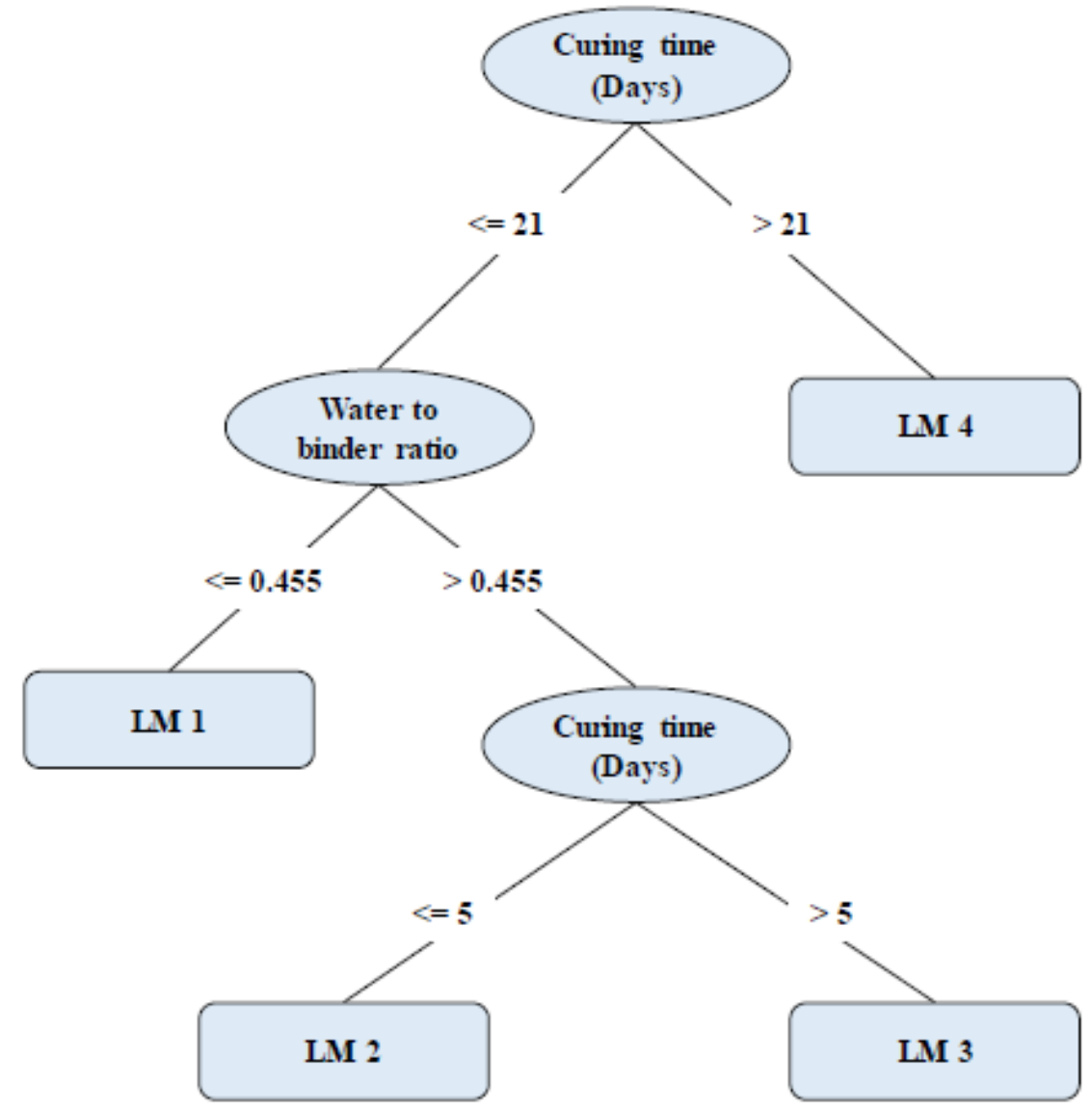

Figure 11

Pruned M5P-tree model 

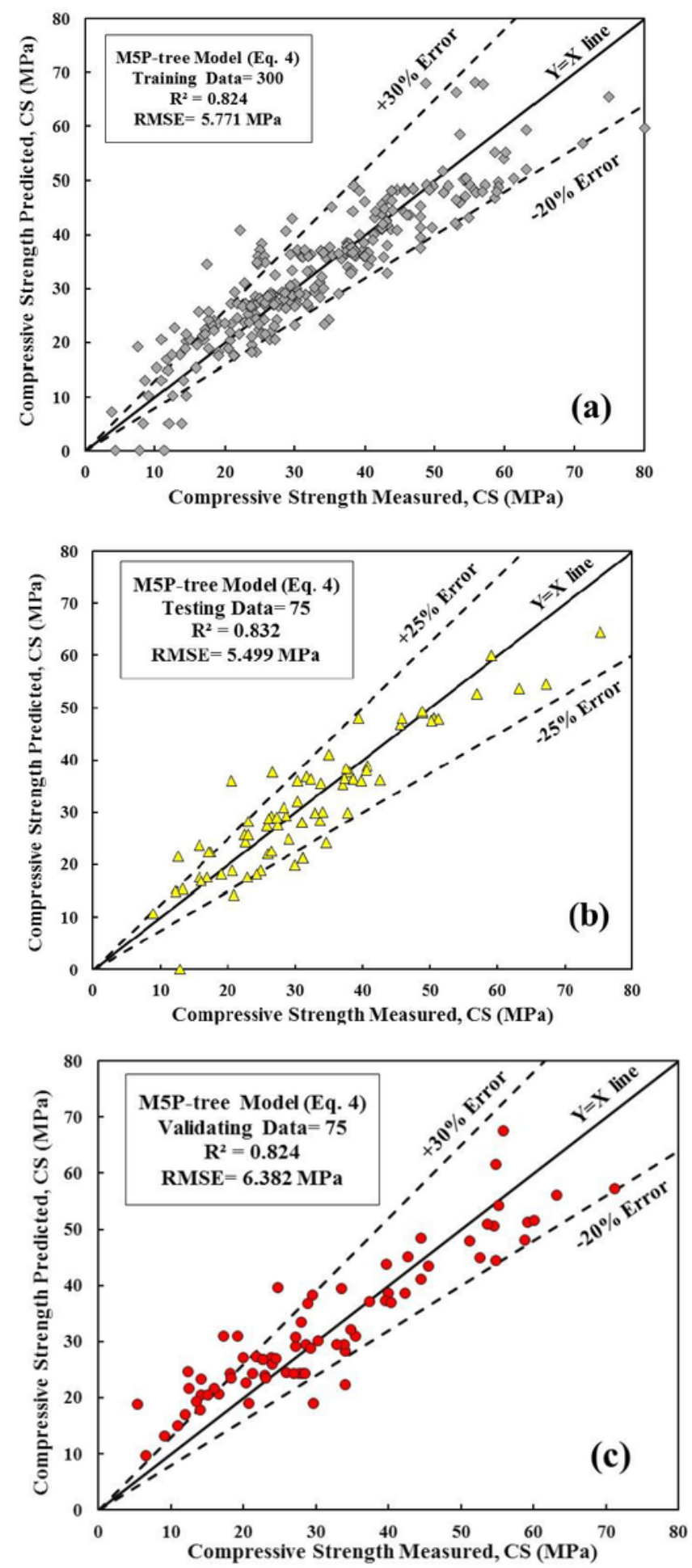

Figure 12

Variation of CS Predicted with CS Measured using M5P-tree model (a) training data, (b) testing data, and (c) validating data 

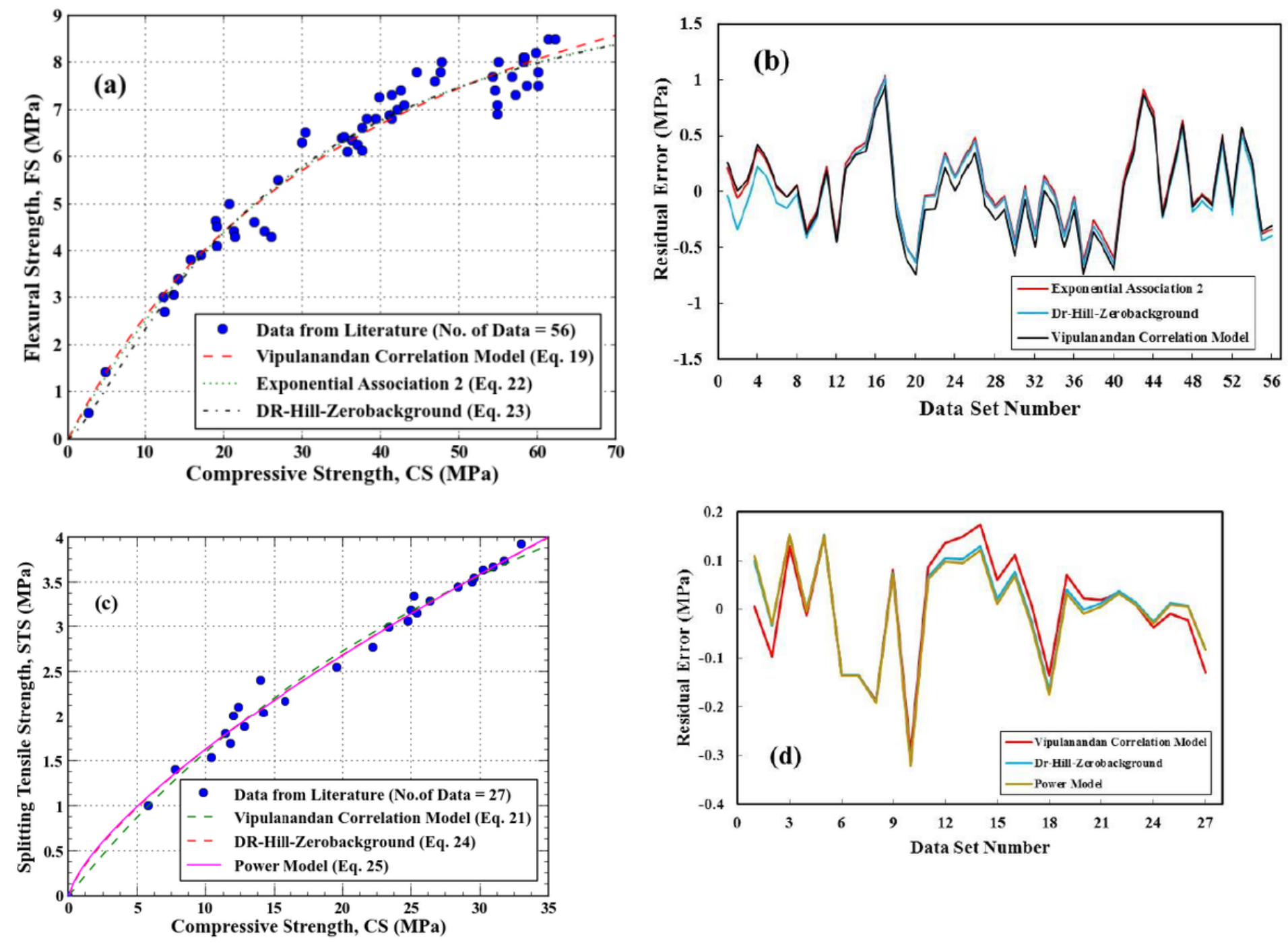

\section{Figure 13}

Comparing models for flexural strength, splitting tensile strength, and compressive strength correlation using (a) variation of FS with CS, (b) residual error to predict FS, (c) variation of STS with CS, and (d) residual error to predict STS 

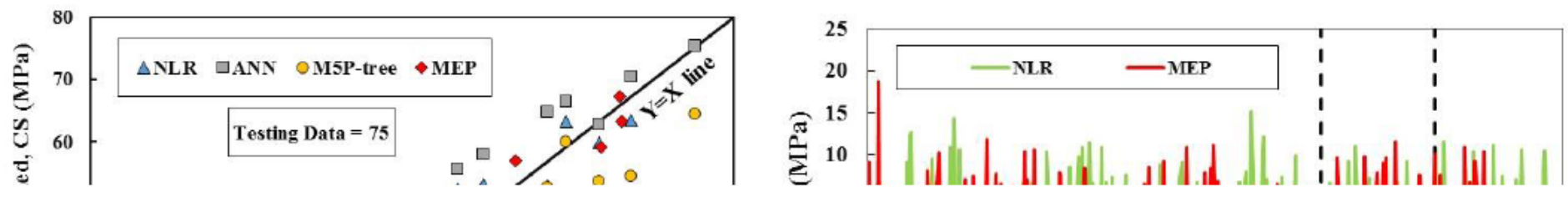

\section{Figure 14}

Comparison of developed model based on (a) variation between measured and predicted CS values for testing data and (b) residual error for the MEP and NLR models (c) residual error for the MEP and ANN models (d) residual error for the MEP and M5P-tree models
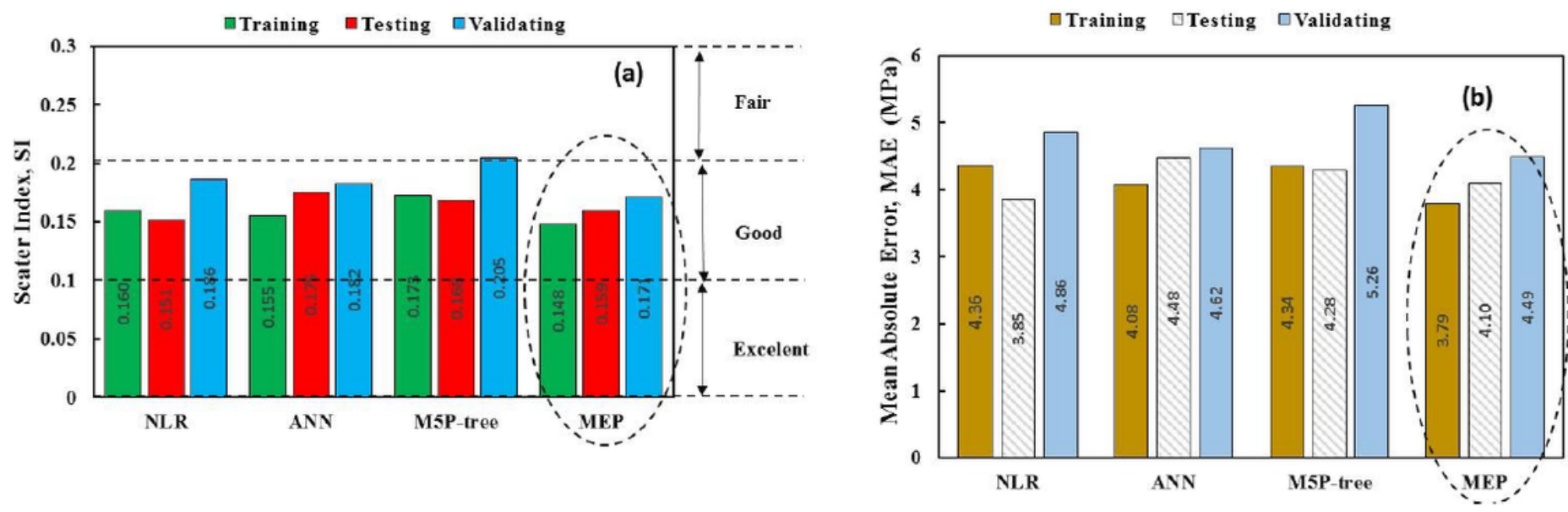

Figure 15 

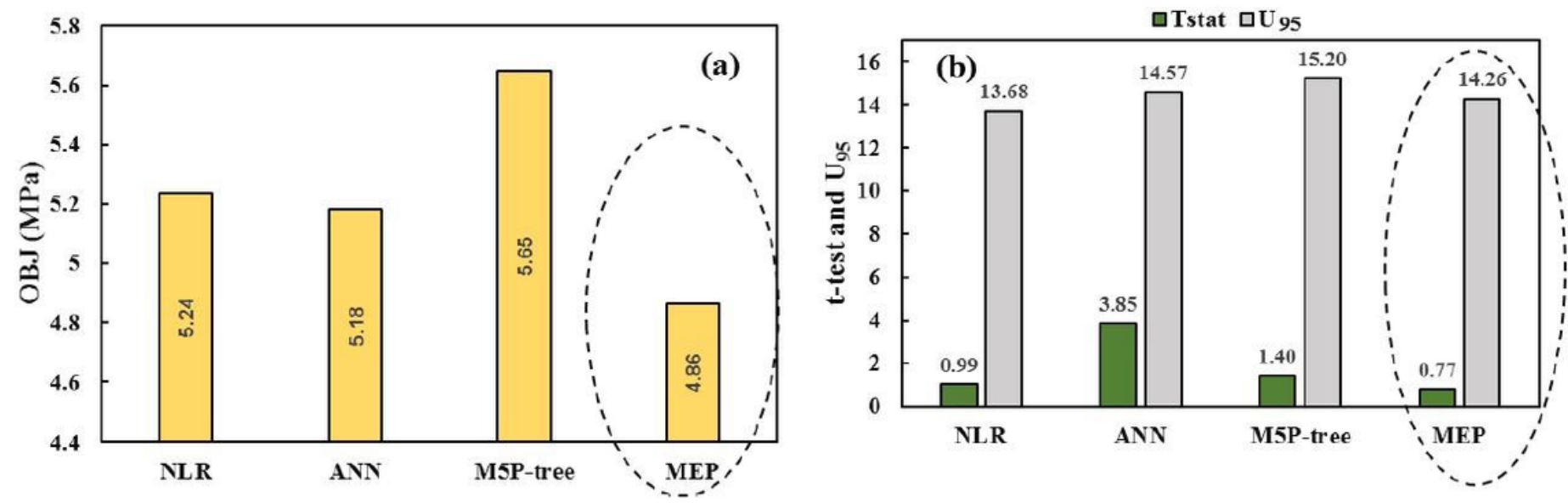

Figure 16

Comparing developed models based on (a) OBJ and (b) T-stat and $\mathrm{U}_{95}$

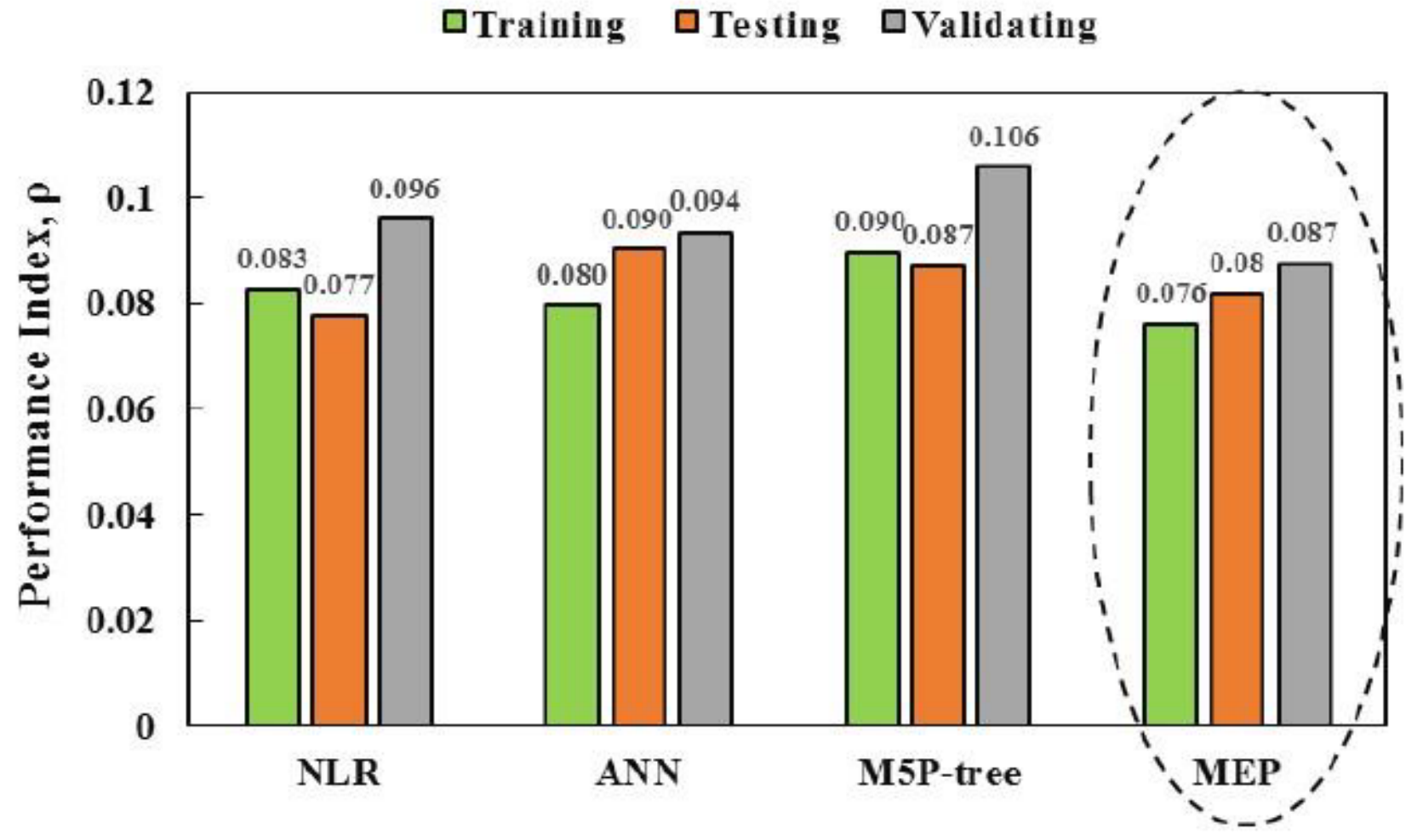

Figure 17

Comparing developed models using performance index 

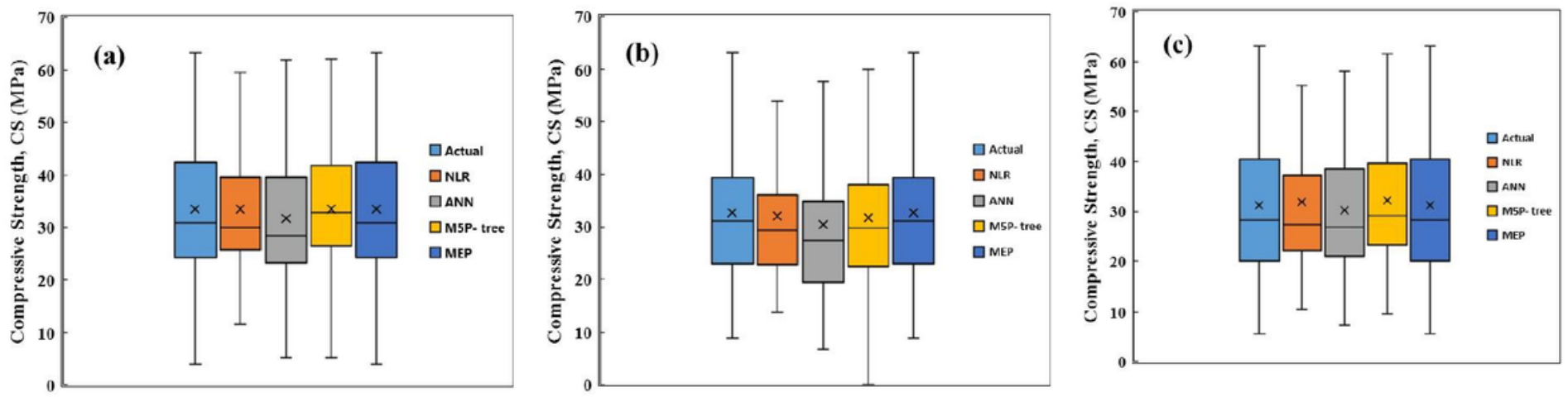

\section{Figure 18}

Comparing developed models using boxplot for actual and predicted compressive strength values (a) training data, (b) testing data, and (c) validating data 